Report No. BMI-1166

Reactors - Power

(M-3679, 19th Ed.)

Contract No. W-7405-eng-92

\title{
HAZARDS SUMMARY REPORT
}

for the

REFLECTOR-CONTROL CRITICAL-ASSEMBLY EXPERIMENTS

by

Francis J. Jankowskı

William S. Hogan

Robert F. Redmond

Joel W. Chastain

Sherwood L. Fawcett

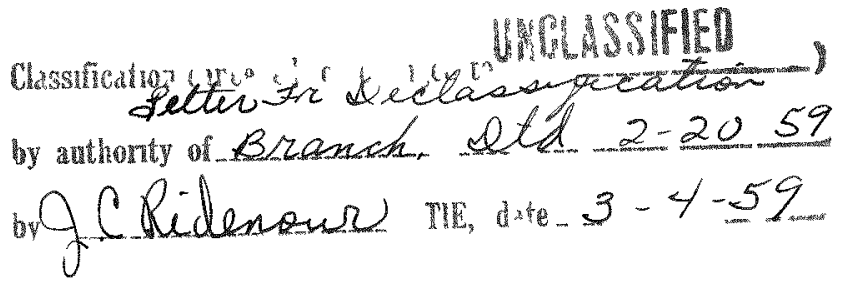

February 12, 1957

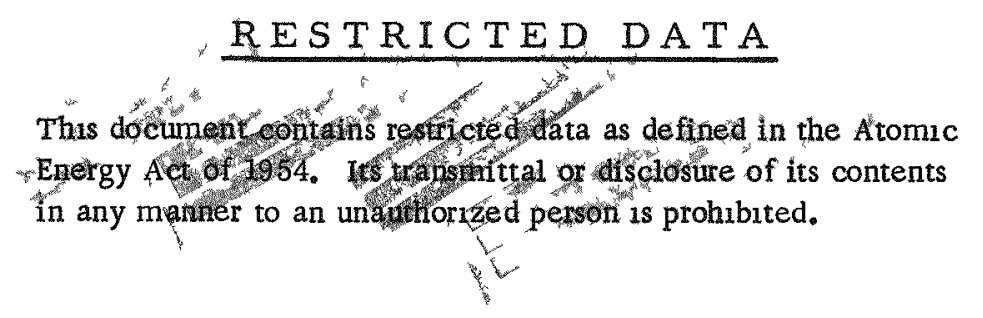

BATTELLE MEMORIAL INSTITUTE

$505 \mathrm{~K}$ ing Avenue

Columbus 1, Ohio 


\section{DISCLAIMER}

This report was prepared as an account of work sponsored by an agency of the United States Government. Neither the United States Government nor any agency Thereof, nor any of their employees, makes any warranty, express or implied, or assumes any legal liability or responsibility for the accuracy, completeness, or usefulness of any information, apparatus, product, or process disclosed, or represents that its use would not infringe privately owned rights. Reference herein to any specific commercial product, process, or service by trade name, trademark, manufacturer, or otherwise does not necessarily constitute or imply its endorsement, recommendation, or favoring by the United States Government or any agency thereof. The views and opinions of authors expressed herein do not necessarily state or reflect those of the United States Government or any agency thereof. 


\section{DISCLAIMER}

Portions of this document may be illegible in electronic image products. Images are produced from the best available original document. 


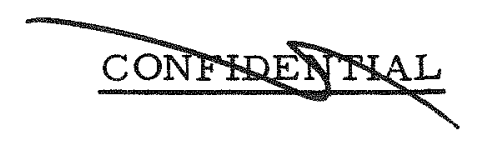

TABLE OF CONTENTS

Page

ABSTRACT . . . . . . . . . . . . . . . . . 5

INTRODUCTION . . . . . . . . . . . . . . . . . 5

Critical Facility . . . . . . . . . . . . . . 6

Purpose of the Experiment . . . . . . . . . . . 7

REACTOR AND ITS OPERATION . . . . . . . . . . . . . 8

Site Location and Description . . . . . . . . . . . 8

Critical-Assembly Building . . . . . . . . . . . . 8

Assembly Room . . . . . . . . . . . . . 14

Control Room . . . . . . . . . . . . . . 17

Storage Vault . . . . . . . . . . . . . . 17

Counting Room . . . . . . . . . . . . . . . . 17

Office and Laboratories . . . . . . . . . . . . 17

Description of Reactor Assemblies . . . . . . . . . . 18

Power Reactor ................. . 18

Critical Assembly . . . . . . . . . . . . 18

Control of Critical Assembly . . . . . . . . . . . 23

Mechanical and Electrical Controls . . . . . . . 23

Source Drive . . . . . . . . . . . . . . 28

Table Drive ... . . . . . . . . . . . . 28

Control and Research Instrumentation . . . . . . . 30

Plan of Operation and Types of Experiments . . . . . . . 34

Approach to Critical . . . . . . . . . . . . 34

Control-Rod Calibrations . . . . . . . . . 35

Other Reactor Experiments . . . . . . . . . . 35

Assembling Operations............ . . . 36

Precritical Operation Check-Out . . . . . . . . 36

Processing and Disposal of Radioactive Materials and Solutions . . . . . . . . . . . . 37

Limitations . . . . . . . . . . . . . . 37

Special Characteristics of the Critical Assembly . . . . . 37

Safety Mechanisms . . . . . . . . . . . . . 39

Control and Safety Rods ............. . 39

Table Separation . . . . . . . . . . . . 40

Electrical Interlocks . . . . . . . . . . . . . 40

Instrumentation . . . . . . . . . . . . . . . 40

MAKE-UP OF SURROUNDING AREA . . . . . . . . . . . . . 42

Population Distribution . . . . . . . . . . . . . . . 42

Industry Adjacent to the Site . . . . . . . . . . . . 43

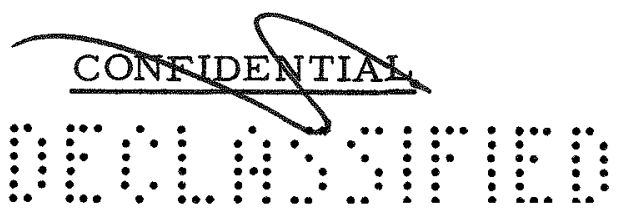




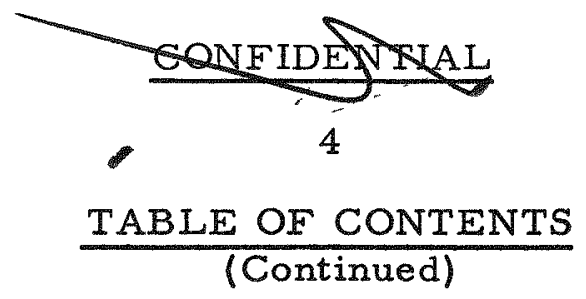

$\underline{\text { Page }}$

Seismology • • • . . . . . . . . . . . 43 43

Climatology . . . . . . . . . . . . . . . . . 43

Geology and Hydrology . . . . . . . . . . . 45

NORMAL OPERATING HAZARDS • . . . . . . . . . . 46

Radiation Level in the Building. . . . . . . . . . 46

Escape of Fission Products . . . . . . . . . . . 47

HAZARDS AFTER AN ACCIDENT . . . . . . . . . . . . 47

Radiation From Radioactive Cloud. . . . . . . . . . . 47

Radiation Due to Fall-Out or Rain-Out From the

Radioactive Cloud . . . . . . . . . . 50

Inhalation of Radioactive Material. . . . . . . . . . 50

POSSIBLE ACCIDENTS • • . . . . . . . . . . . . 54

Possible Reactivity Additions . . . . . . . . . . . 54

Energy Releases . . . . . . . . . . . . . 55

DISCUSSION • . . . . . . . . . . • • . . . 55

REFERENCES . . . . . . . . . . . . . 57

APPENDIX A

LETTERS ON EARTHQUAKES . . . . . . . . . . . . . 59

APPENDIX B

METEOROLOGY REPORT . . . . . . . . . . . 61

APPENDIX C

CONCLUSIONS OF GEOLOGY AND HYDROLOGY REPORT • • . . 67

APPENDIX D

HAZARDS CALCULATIONS . . . . . . . . . . . . . .

APPENDIX E

MISCELLANEOUS CALCULATIONAL METHODS. 


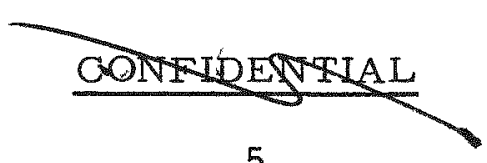

5

\title{
HAZARDS SUMMARY REPORT for the \\ REFLECTOR-CONTROL CRITICAL-ASSEMBLY EXPERIMENTS
}

\author{
Francis J. Jankowski, William S. Hogan, Robert F. Redmond, \\ Joel W. Chastain, and Sherwood L. Fawcett
}

Critical experiments are described and the hazards attendant to these experiments are evaluated for a reflector-controlled boilingheterogeneous-reactor design.

The proposed reactor design is water moderated and reflected. However, to provide maximum flexibility and safety, the critical assembly is a thermal reactor moderated and reflected with plastic having appropriate voids to simulate water. A section of the plastic reflector is movable to represent changes in the water-reflector level. The data obtained using this reflector-controlled assembly is then supplied to an electronic reactor simulator which is connected to a full-scale mock-up of the proposed hydraulic control system. In this manner, the characteristics of the complete system are determined.

The fuel-element assemblies are composed of strips of aluminum and Teflon-coated uranium sandwiched with plastic and encased in aluminum boxes. One-half of the core is on a movable table, while the other half is on a fixed table.

Primary control and safety of the assembly is achieved by inserting or withdrawing sandwrched stainless steel-cadmium regulating and safety plates and by increasing or decreasing the distance between the two core halves. For safety, the maximum normal rate of reactivity addition has been limited to an estimated 0.04 per cent per sec for control-rod withdrawal, table closure, or reflector movement. The system is interlocked so that only one rod can be withdrawn at a time and so that the movable table and rods cannot be moved simultaneously. In addition, criticality cannot be reached by moving the tables together. The scram system can insert all the rods in about 0.4 sec.

Hazards calculations are made to determine the dosage from direct irradiation, fall-out, and inhalation from a radioactive cloud resulting from an accident. The exclusion area is shown to be adequate for even the maximum hypothetical accident.

\section{INTRODUCTION}

For some time, Battelle has been analyzing the stability and feasibility of a reflector-control system for a boiling heterogeneous reactor. The control system utilizes the height of a water reflector surrounding the reactor

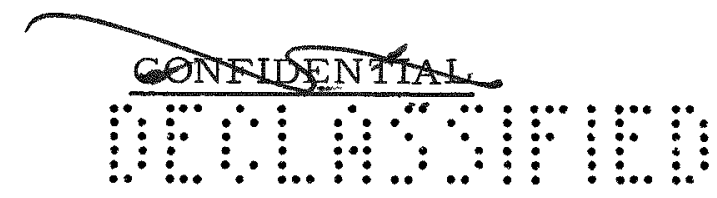




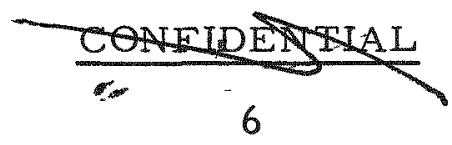

core as a means of controlling the reactor. An annular tank around the core contains the reflector and is connected to an external surge tank. As the steam pressure in the reactor core increases, the water is forced out of the reflector and into the surge tank. This lowers the level of the reflector, allowing more neutrons to leak out, which, in turn, decreases the reactor power. This method of control appears promising as a means for making a power reactor stable and self-controlling for load changes and long-term changes caused by burnup and fission-product poisons. The results of detailed analyses showed the system to be stable and practicable. Consequently, the next step, an experimental evaluation, is being undertaken.

To obtain results on the operation of the complete reactor system, two separate experiments are proposed. In the first of these, called Phase A, the kinetics of the control system will be investigated by building a fullscale mock-up of the hydraulic system. This system will be "driven" by suitable electronic equipment representing the reactor.

In the second experiment, Phase B, a critical assembly will be constructed and operated to determine experimentally the necessary physics and core-design parameters for such a reflector-controlled reactor. Also, this experiment will help optimize the design of the core and reflector complex. These data will be fed back to be used in the simulator for the hydraulics study.

Critical Facility

The boiling feature of the proposed power reactor is not new in reactor work. The LITR at Oak Ridge has been allowed to boil in stability experiments. The BORAX reactors have been allowed to boil, particularly the BORAX-III experiments in which power was extracted from the reactor by boiling. The SPERT series of experiments has also been of this nature and has yielded data on the operation of boiling reactors. One disadvantage of the direct boiling cycle is that it is not stable with respect to power demand. With the BORAX-III reactor, the power was adjusted by use of control rods when the power demand was changed.

In general, water-moderated reactors are usually studied by the use of water-moderated critical assemblies. However, the inclusion of a variable-height reflector increases the design complexities of the critical assembly and the use of water for the critical assembly has several drawbacks. The first of these is the inflexibility of handling water in the reflector system in a critical experiment. A much larger drawback occurs because the proposed reflector-controlled power reactor will have a large void fraction when operating at power. If this void fraction is included in a

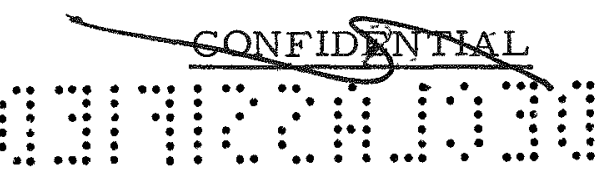




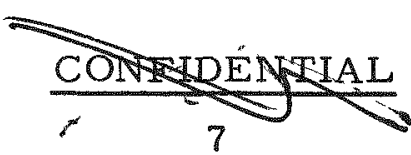

water-moderated critical assembly, the possibility exists that a sizable portion of the void could be filled accidentally with water, causing a hazardous situation。

To avoid these difficulties, the inflexibility of a safe water-reflector system and the danger of loss of voids in a water moderator, it is proposed to construct a plastic-moderated critical assembly. In this critical assembly, the reflector will be constructed by stacking sheets or blocks of plastic. This will preclude any sudden change in reflector height. The voids required in the reactor core will be produced by punching or drilling holes in the plastic moderator or by leaving voids in other manners. This will produce a safe facility from an operational point of view.

The use of plastic to simulate water in a critical facility has been used frequently at KAPL. The KAPL group has found it advantageous to use plastic to mock up water-moderated reactors and has been operating such a facility, their Flexible Plastic Reactor (FPR), since February 1, 1956.

\section{Purpose of the Experiment}

In general, the control range and effectiveness of the reflector and information which will permit an evaluation of the transient behavior will be obtained from this experiment. At the present time, the following specific measurements are planned:

(1) A determination of the critical mass under various conditions of reflector position, core-moderator density, and void distribution

(2) Flux and power distributions under various conditions

(3) The incremental worth of the reflector obtained by adjusting control rods and by moving the reflector upward a small distance at several reflector heights

(4) The worth of a burnable poison which is considered to be in a constant ratio to the fuel.

As the program progresses, it may be necessary to include an investigation of the effect of varying other parameters such as height-todiameter ratio of the core, the metal-to-moderator ratio, and the thickness of both the movable and stationary portions of the lateral reflector. 


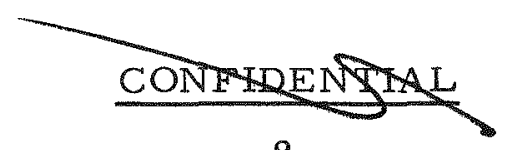

8

REACTOR AND ITS OPERATION

Site Location and Description

The site of the Critical Assembly Laboratory is in Madison County, Ohio, 15 miles west from downtown Columbus. The property faces on the Georgesville-Plain City Road, an improved county highway which is not heavily travelled. The Battelle-owned land is bounded on the south by the Pennsylvania Railroad and on the east by Big Darby Creek, which is the boundary between Franklin and Madison Counties. The tract contains a total of 400 acres and extends about $5000 \mathrm{ft}$ north from the railroad tracks. Figure 1 is a topographic map showing the site in relation to Columbus and the surrounding area.

The Critical Assembly Laboratory is one of three buildings at the Battelle Atomic Energy Center, which is located at the northern end of this property. The location of these buildings with respect to each other and the details of the immediate vicinity are shown in Figure 2. Figure 3 is an aerial photograph of the area and shows a portion of the Battelle land. The Critical Assembly Laboratory is labelled ZPR. The nearest boundary of the property is over $1200 \mathrm{ft}$ from the building.

The surrounding area is a farming community and is sparsely populated. The closest town is West Jefferson, population 2500, which is about 2 miles southwest of the laboratory location. The closest building is a barn, $2000 \mathrm{ft}$ northwest of the site, and the closest dwelling is $3100 \mathrm{ft}$ to the southwest. During the summer months, a Girl Scout camp located across the river is inhabited. The site is about $2000 \mathrm{ft}$ from the camp. The estimated total number of residents within a 1 -mile-radius circle is 60 .

The site is located on level ground having an average elevation of 900 $\mathrm{ft}$ above sea level. The average elevation of downtown Columbus is approximately $750 \mathrm{ft}$. The change in elevation from the site to downtown Columbus takes place by a gradual rise over the 15-mile interval. A flat-bottom ravine about $40 \mathrm{ft}$ deep crosses the plot from east to west and is the bed of a small intermittent stream. The Big Darby Creek flows in a broad valley along the eastern boundary of the property and is approximately $50 \mathrm{ft}$ below the elevation of the site.

Critical-Assembly Building

The Critical Assembly Laboratory is a building having $10,500 \mathrm{ft}^{2}$ of floor space. The building contains the reactor-assembly room, a control room, a vault, a counting room, an instrument laboratory, a shop, and

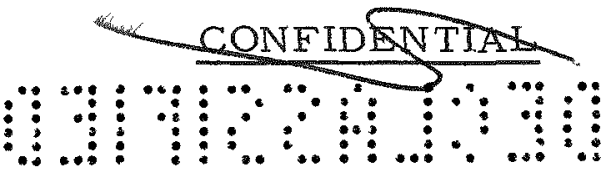


CONFDESTAL

9 and 10

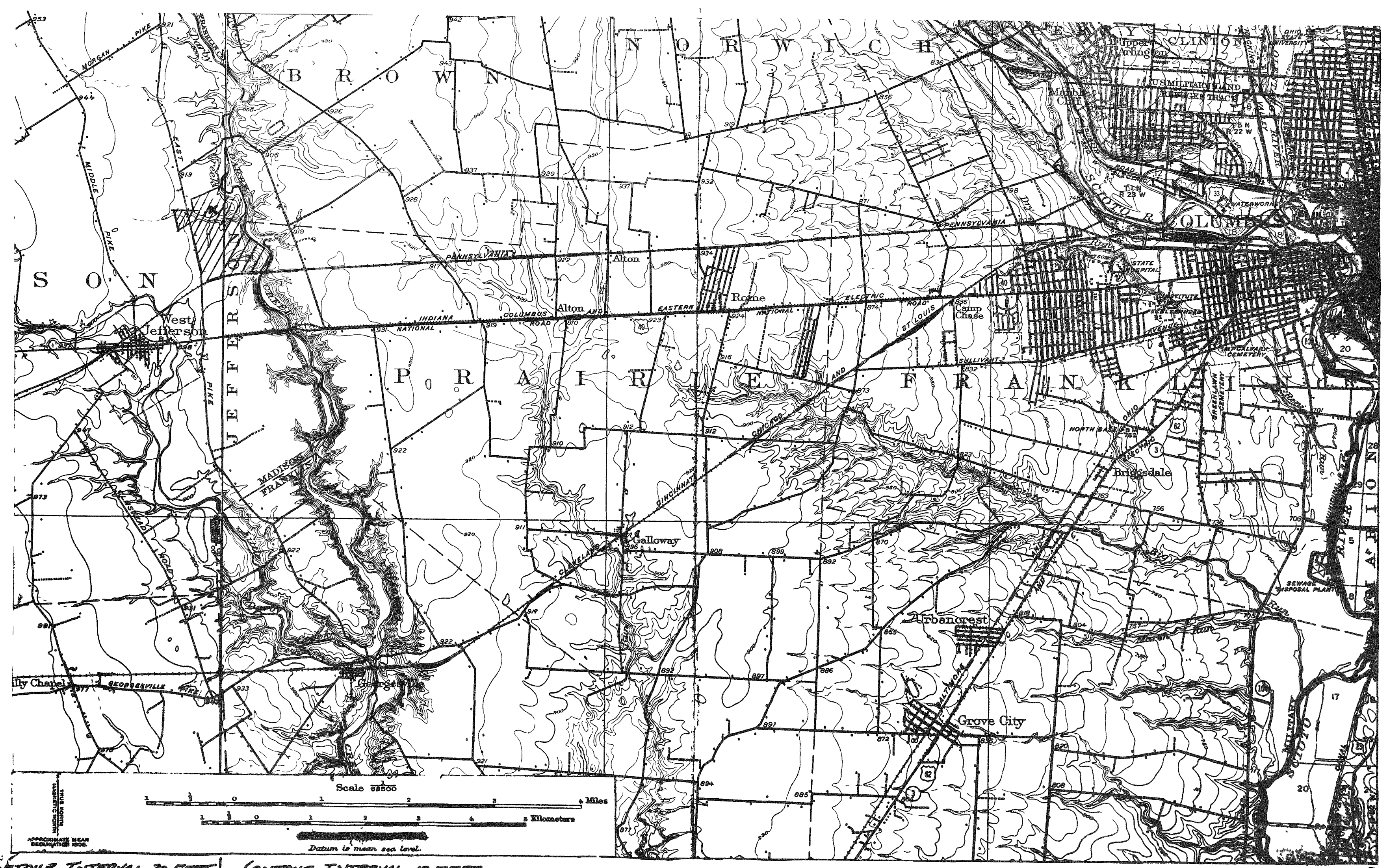

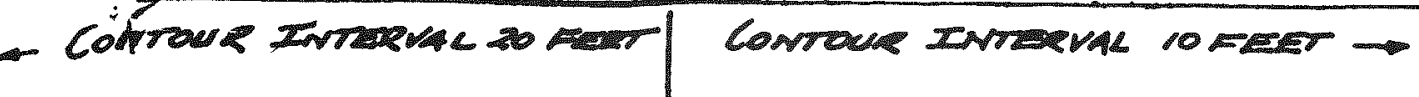

FIGURE 1. TOPOGRAPHICAL MAP

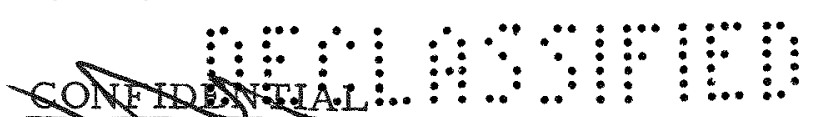

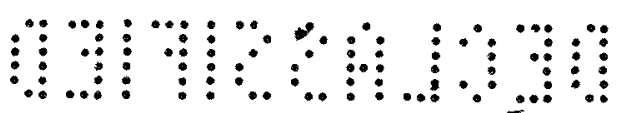


:

$\ldots$

$\because \cdot \cdots$

$\therefore: . .$.

$\vdots \ldots . .$.

....:.:

$\because \because$

$\because \because$

$\because \because \cdots$

$\therefore$

$\therefore .$.

:...:.: 


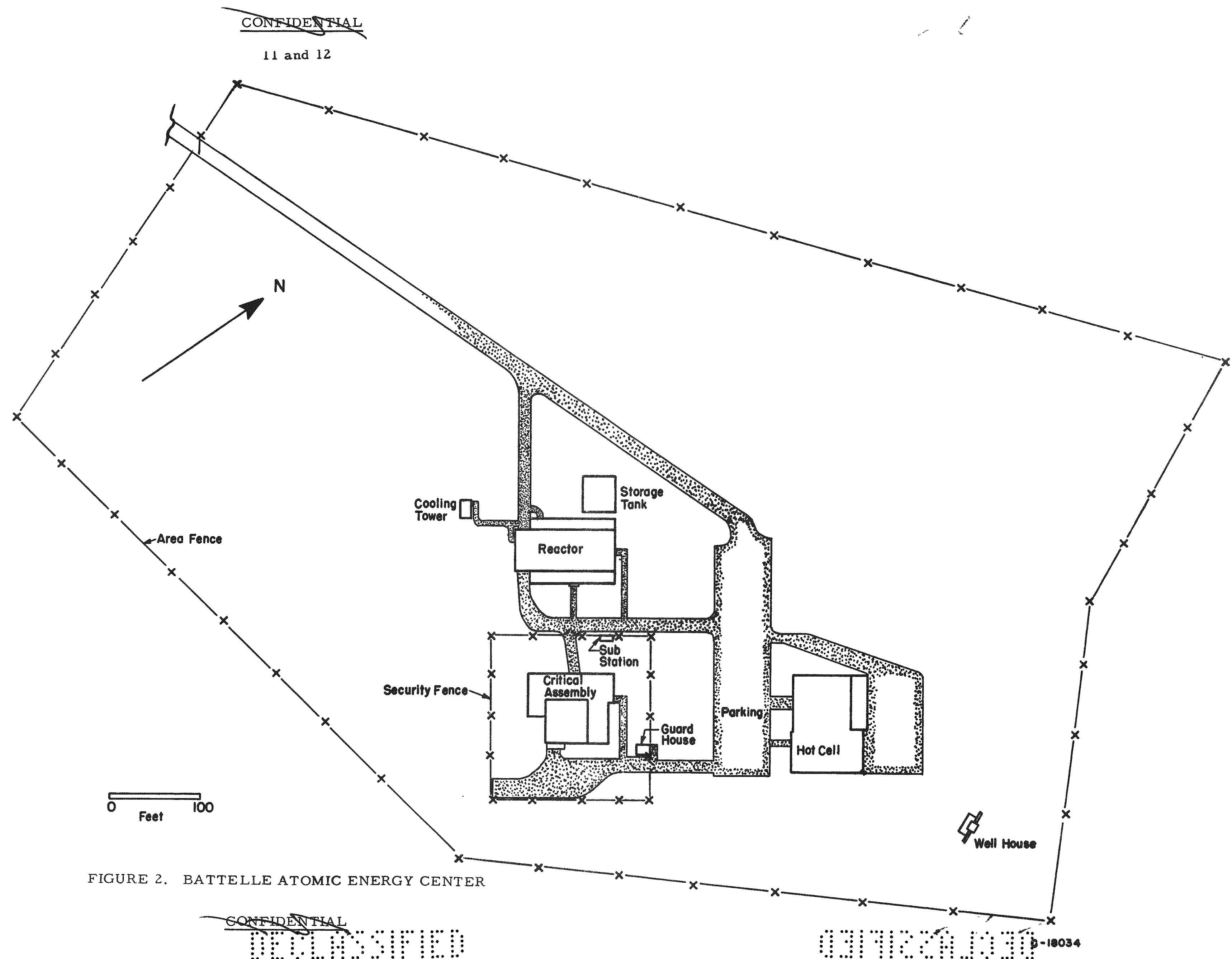


$\cdots$

$\because$

$\because \cdots$

$\ldots$

$\because$.

$\therefore \therefore$

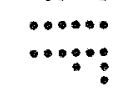

$\because \cdots: .$.

:.....:

$: \cdots: .:$

$\vdots \ldots . .:$

$\ldots . .:$

$\because \because$

$\therefore \because$

$\because \because \cdots$

$\vdots \ldots .$.

$\therefore . .$.

$\vdots . .$.

$\therefore . . .:$ 


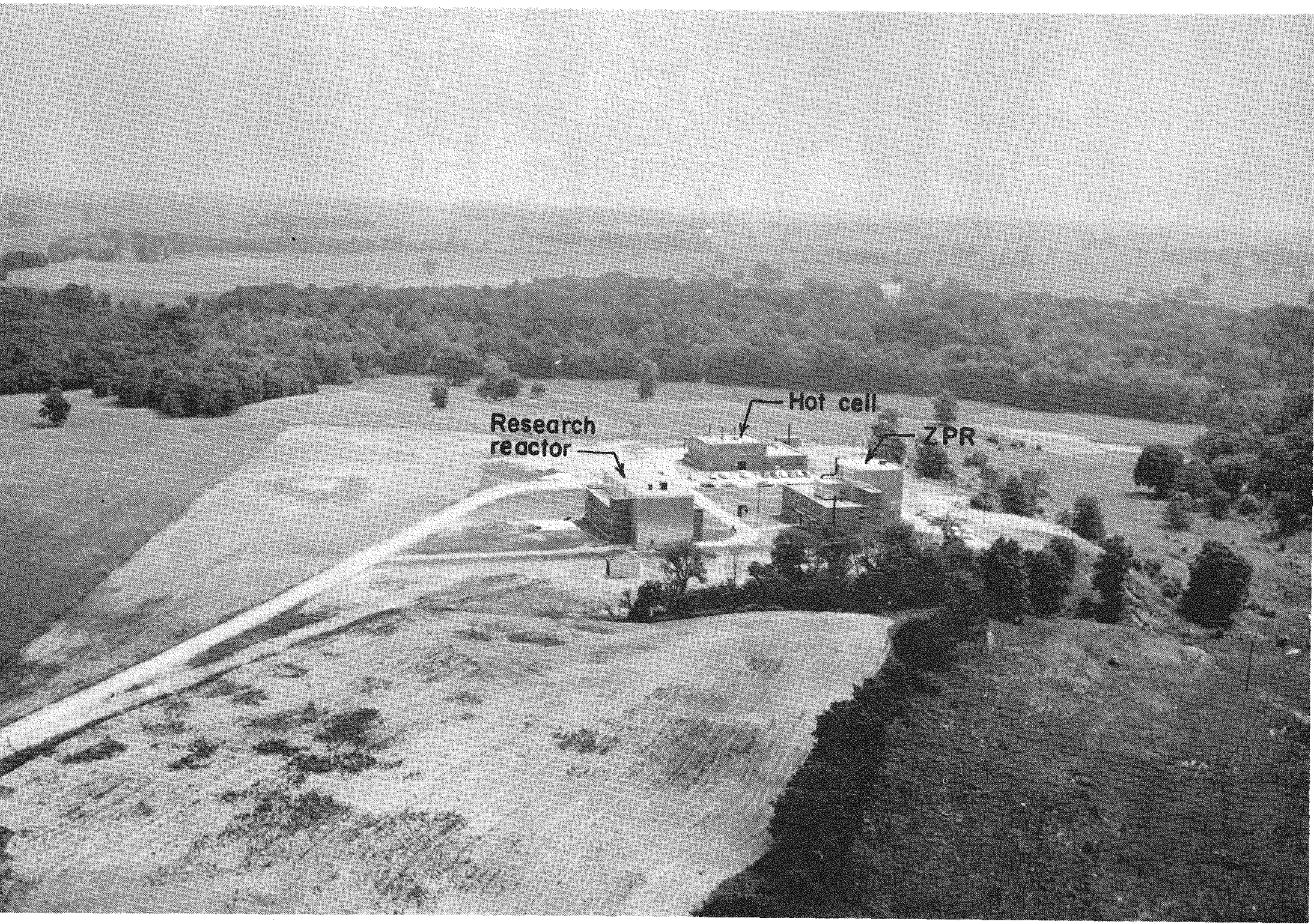

心凅

FIGURE 3. AERIAL PHOTOGRAPH OF BATTELLE ATOMIC ENERGY CENTER 


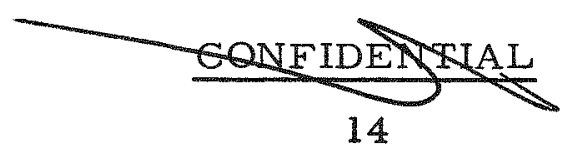

rooms which may be used as offices or laboratory space. The first and second floor plans are shown in Figure 4. The building is constructed of concrete block faced with brick, with a structural-steel frame, except for the storage vault and assembly room. The storage vault is constructed entirely of reinforced poured concrete. The assembly-room walls are $2 \mathrm{ft}$ thick up to a height of $26 \mathrm{ft}$. The wall above this and the roof are Q-panel aluminum siding. All of this is supported by a heavy structural-steel frame.

The arrangement of the assembly room, control room, and vault, and the associated stairwell, forms an area which can be shut off from the rest of the building.

The power provided for the installation is $300 \mathrm{kva}$. Other utilities are compressed air, demineralized water, natural gas, and a 3-in. water-supply main. Battery-powered emergency lights are provided in the assembly and control rooms.

The building is heated by forced-hot-water heat. The temperature is controlled by thermostats in the assembly room and by valves on the individual heaters in other locations. The control room, the instrument laboratory, and the counting room are air conditioned.

\section{Assembly Room}

The reactor-assembly room is approximately $40 \mathrm{ft}$ square and 50 ft high. The three walls facing into the building are of reinforced poured concrete $2 \mathrm{ft}$ thick. The other wall is 1 -ft-thick poured concrete. This concrete extends to a height of 26 feet, which is enough to shield personnel in the inhabited portion of the building. Above this height the walls are constructed of Q-panel aluminum metal siding on the outside and steel sheets on the inside. The Q-panels have caulking material between them. The steel plates have lead tapes sealing the seams. This type of construction furnishes a tight enclosure so that activity from a possible accident will be contained or will be released very slowly to the atmosphere if the building is not damaged by the accident. The siding above the solid concrete wall is supported by structural-steel framework, which also supports a 10-ton crane. The roof is built up of asphalt and gravel over heavy building paper and is supported by a Q-panel metal deck.

A large exhaust fan located in a penthouse above the office area supplies fresh air to the room. The exhaust is through the ceiling. Both the air inlet and the exhaust opening are equipped with louvers and a solenoidoperated sheet-metal plate to make the openings tight when the fan is not in operation.

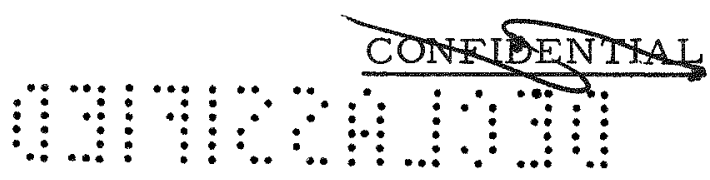




\section{CONFLENTMA}

15 and 16

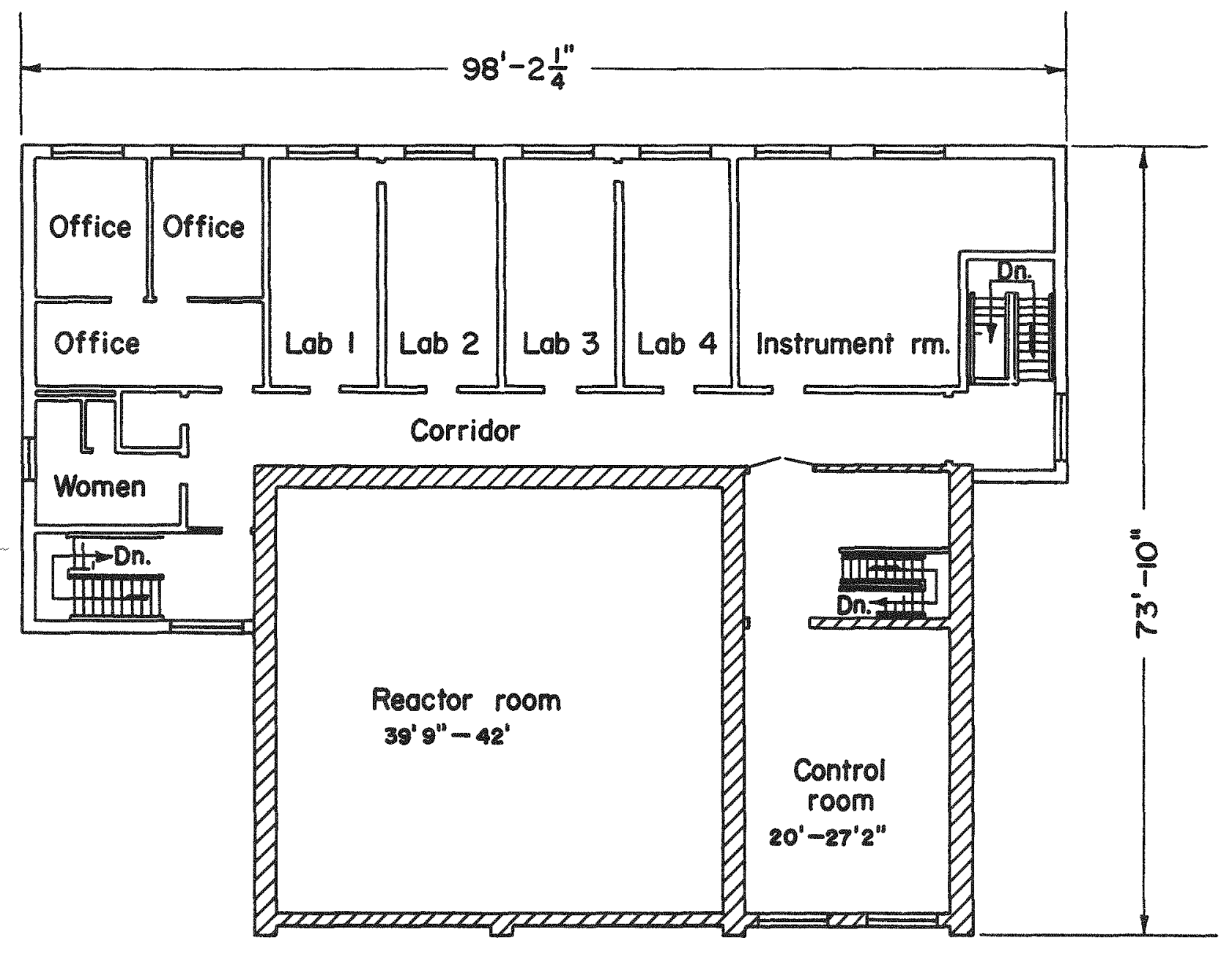

Second Floor Plan

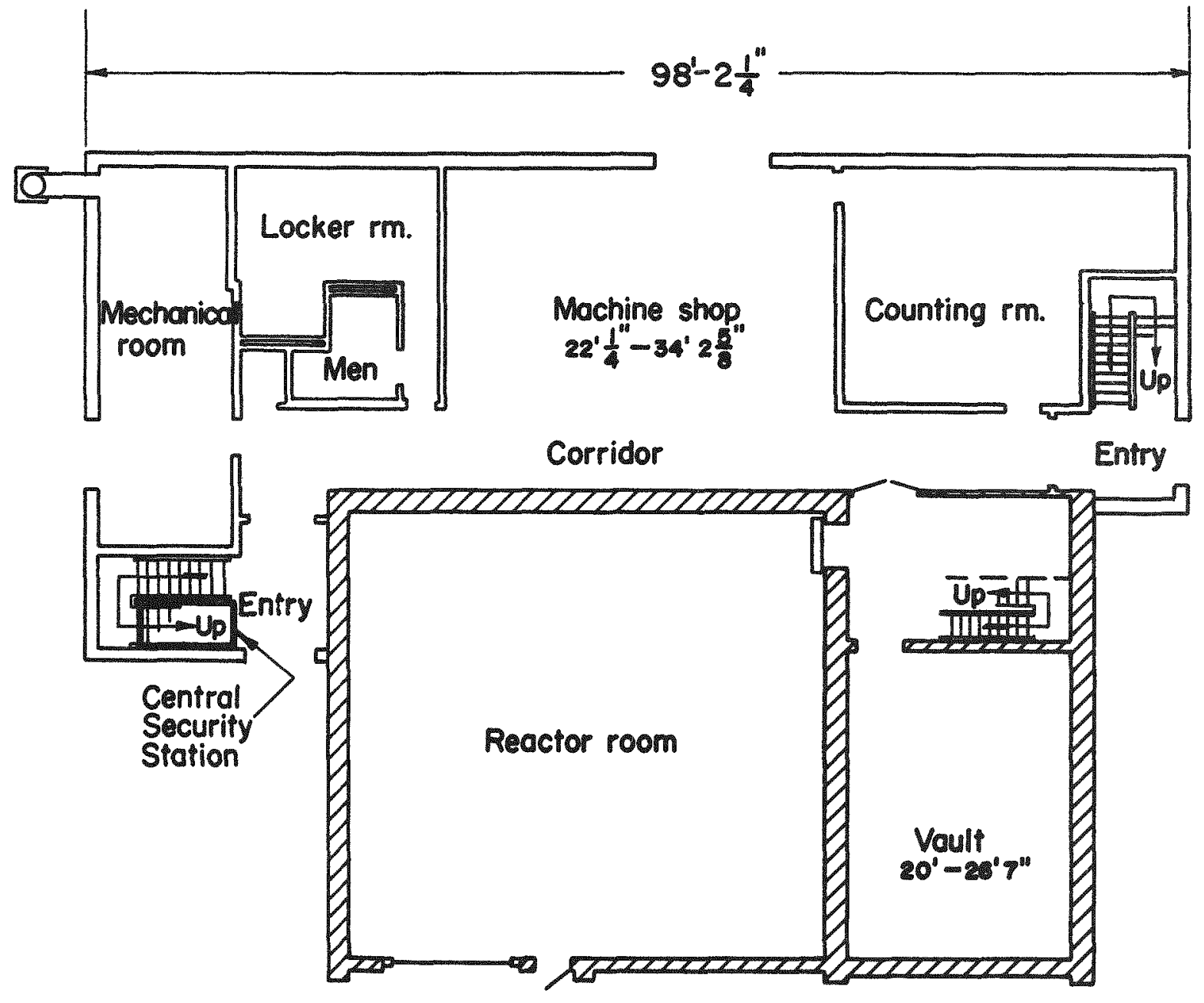

First Floor Plon

Critical assembly areo WZZZA

FIGURE 4. FLOOR PLAN OF CRITICAL ASSEMBLY BUILDING

$$
\text { CONEPENTAL }
$$


$\because \cdots$

:......

$\therefore \therefore$

$\therefore \therefore$

:...:

$\because \cdots:$

$\vdots \cdots$

:...:.:

$\vdots \ldots .$.

$\ldots . . .: 5$

$\because \because$

$\because \because$

$\because \because \cdots$

$\vdots \ldots$

$\therefore \ldots$

$\vdots . . .: \vdots$

$\therefore . .$. 


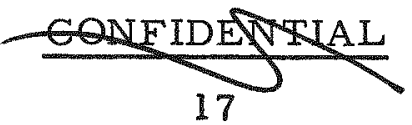

The assembly room has a single entrance into the remaining part of the building which can be closed off with a steel and concrete door having gamma-shielding properties equivalent to the $2-\mathrm{ft}$ wall. In addition to this door, there is a personnel entrance and a truck entrance to the outside which will be kept closed and locked during reactor operations.

There are a number of 4 -in. conduit openings between the assembly room and control room for the passage of control wiring. These openings are at a 45-deg angle above head height to prevent radiation streaming from the openings from reaching personnel. The openings which are not in use will be fitted with shielding plugs. The ones in use will be filled with a material to make them reasonably gas tight.

\section{Control Room}

The control room is located on the second floor adjacent to the as sembly room. It is approximately $20 \mathrm{ft}$ wide and $27 \mathrm{ft}$ long. Services in this room include air conditioning and a dehumidifier. The control and research instrumentation are located along one wall.

\section{Storage Vault}

The storage vault is on the first floor beneath the control room and is approximately the same size, that is, $20 \mathrm{by} 27 \mathrm{ft}$. The walls, floor, and ceiling are of reinforced-concrete construction. Two walls, the floor, and ceiling are 1 -ft-thick reinforced concrete. The remaining two walls are 2ft-thick concrete. The steel vault-type door is equipped with a four-tumbler manipulation-proof combination lock.

\section{Counting Room}

The counting room is located on the first floor so that the use of heavy shielding will not be a problem and so that foils of short half life can be removed from the assembly room to the counting room with a minimum delay. The room is approximately $21 \mathrm{ft}$ square. No special wall construction is provided and shielding will be provided for individual detectors as required. There is a grounded bus bar running around the room. Air conditioning is provided to maintain the air at $75 \mathrm{~F}$ and 50 per cent relative humidity.

\section{Office and Laboratories}

Approximately $750 \mathrm{ft}^{2}$ of floor space is provided on the first floor for a machine shop. Equipment in this shop includes a power hacksaw, a band

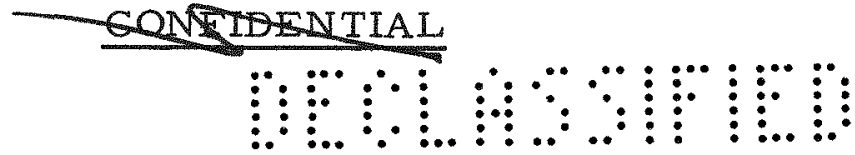




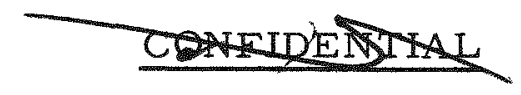

saw, a lathe, a drill press, a milling machine, a number of benches, and an assortment of hand tools. The machine shop has a truck entrance for bringing in bulky equipment.

An electronic laboratory for repairing instruments and for building up and modifying the instruments as required is located on the second floor above the counting room. This laboratory is air conditioned.

Seven additional rooms on the second floor provide space for offices, for a conference room, and for laboratory space, should it be required.

\section{Description of Reactor Assemblies}

The proposed general type of power reactor for which these studies are being made is described briefly below. The critical assembly to be used in these studies, along with the associated controls and instrumentation, is described in greater detail.

\section{Power Reactor}

The reactor design on which these studies are based has a core which is approximately a $2-\mathrm{ft}$ cube. The fuel elements are an aluminum-uraniumnickel alloy using $-93.5 \mathrm{w} / \mathrm{o}$ enriched uranium. The nickel content is low $(\sim 1 \mathrm{w} / 0)$ and is added for corrosion resistance. The fuel elements are plates similar to MTR-type elements and light water is used as the coolant and moderator. The reactor will be operated in the boiling condition with about 11.5 per cent maximum void in the water.

The control of the reactor will be effected by variation of the lateral reflector height and, if necessary, this will be supplemented by control elements. The control elements will be of stainless steel-cadmium sandwich construction of either the flat-plate or cross-shape type.

The critical-assembly work will attempt to evaluate the reflectorcontrol scheme for different reactor operating conditions.

\section{Critical Assembly}

The core and reflector will be mounted on a table assembly. The core will be divided into two halves identical in every respect except that one half will be stationary and the other half movable.

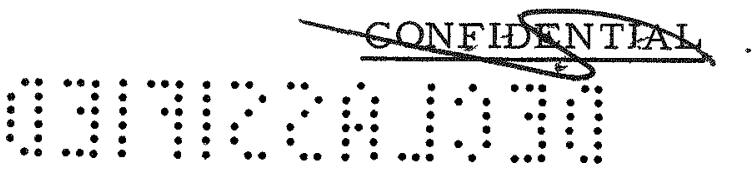




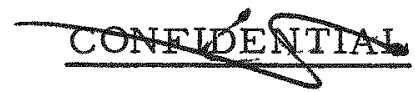

19

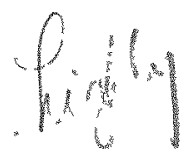

The reactor core (see Figure 5) will be made up of fuel elements which will be $1-1 / 2$ by $1-1 / 2$ by $43-$ in. boxes made of $63-S$ aluminum. The boxes will have a 1/16-in. -thick wall. These boxes will contain drawerlike inserts which in turn will contain strips of aluminum, polyethylene (to simulate water), and(fully) enriched uranium. The uranium will be 0.004 by 0.5 by 24-in. foil coated with Teflon. Besides the 24-in, -long simulated fuel element, the tubes will also contain 6 in. of polyethylene on the bottom and $1 \mathrm{ft}$ on the top to simulate the water reflector. The fueled tubes will be mounted between two adjustable grids supported by aluminum side plates. These plates will be fastened to the table base plate. The core arrangement is flexible and allows for changing safety-rod positions and core size. The core will be surrounded by a lateral polyethylene reflector $1 \mathrm{ft}$ thick. The polyethylene will contain voids to simulate desired water-density conditions.

The lateral 6-in. thickness of polyethylene reflector next to the core will be removable so that the height of this annular gap can be varied by hand stacking. These blocks will be held secure by vertical rods which will extend through a stack and be fastened to the steel plates that contain the reflector and core. The core will be an approximately 2 -ft cube for the initial measurements. This geometry may be changed if it appears desirable. The control and safety plates will move vertically and will be of stainless steelcadmium sandwich construction. They will have a polyethylene extension on the bottom to simulate water entering as rods are withdrawn. These elements will be 4-1/2 in. wide and 1/8 in. thick. Fuel elements will serve as safety-plate guides in the core-reflector assembly.

The movable portion of the table will ride horizontally on rails and be driven by a d-c motor supplied by a thyratron rectifier unit. The motor will be coupled to a lead screw through a chain drive, and the lead screw will be attached to the table through a nut. The speed of closing of the table will be changed by limit switches and predetermined by potentiometer settings in the thyratron grid circuits. Design speeds are 25 in. per min from a 48 to a 12-in. separation, 6 in. per min from a 12 to a 2 -in. separation, and $1 / 2$ in. per $m$ in from a 2 -in. separation to the closed position. The opening speed will be 25 in. per min. The entire assembly will be mounted on a steel base frame which will provide a level surface. The position and speed of the movable table will be measured and registered at the console by Selsyns and tachometers, as required to attain sufficient accuracy. The table position can be read to $0.001 \mathrm{in}$. during the final $2 \mathrm{in}$. of travel and to $0.01 \mathrm{in.}$ elsewhere.

Each table half will be made of four 12-in. I-beams. Two of the beams will form the lower support and will be connected by cross beams and a steel deck plate. The other two beams will support the safety rods and the rod drives. These beams will be supported by four columns which rest on the lower beams. The tables will be $5 \mathrm{ft}$ wide by $9 \mathrm{ft}$ long by $13-3 / 4 \mathrm{ft}$ high.

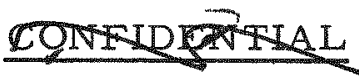


$\therefore \ldots:$

$\vdots \ldots . .8$

(.....

.....:

$\because$.

$\because \because$

$\because:$

$\therefore$

$\therefore$

$\cdots \cdot$ 留

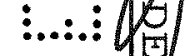

$\therefore \cdots$

密

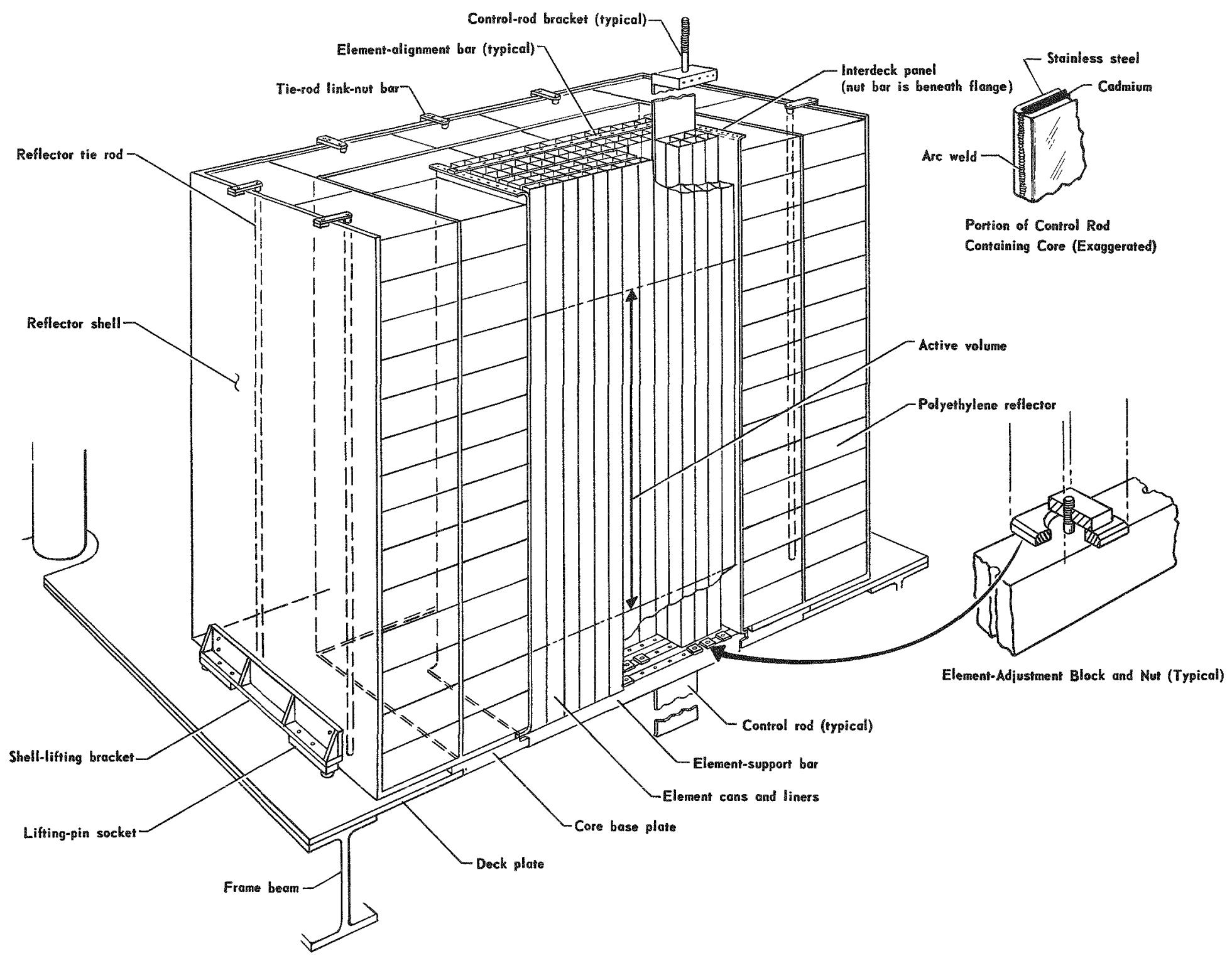

FIGURE 5. CORE-REFLECTOR ASSEMBLY 


\section{CONFTP}

21 and 22

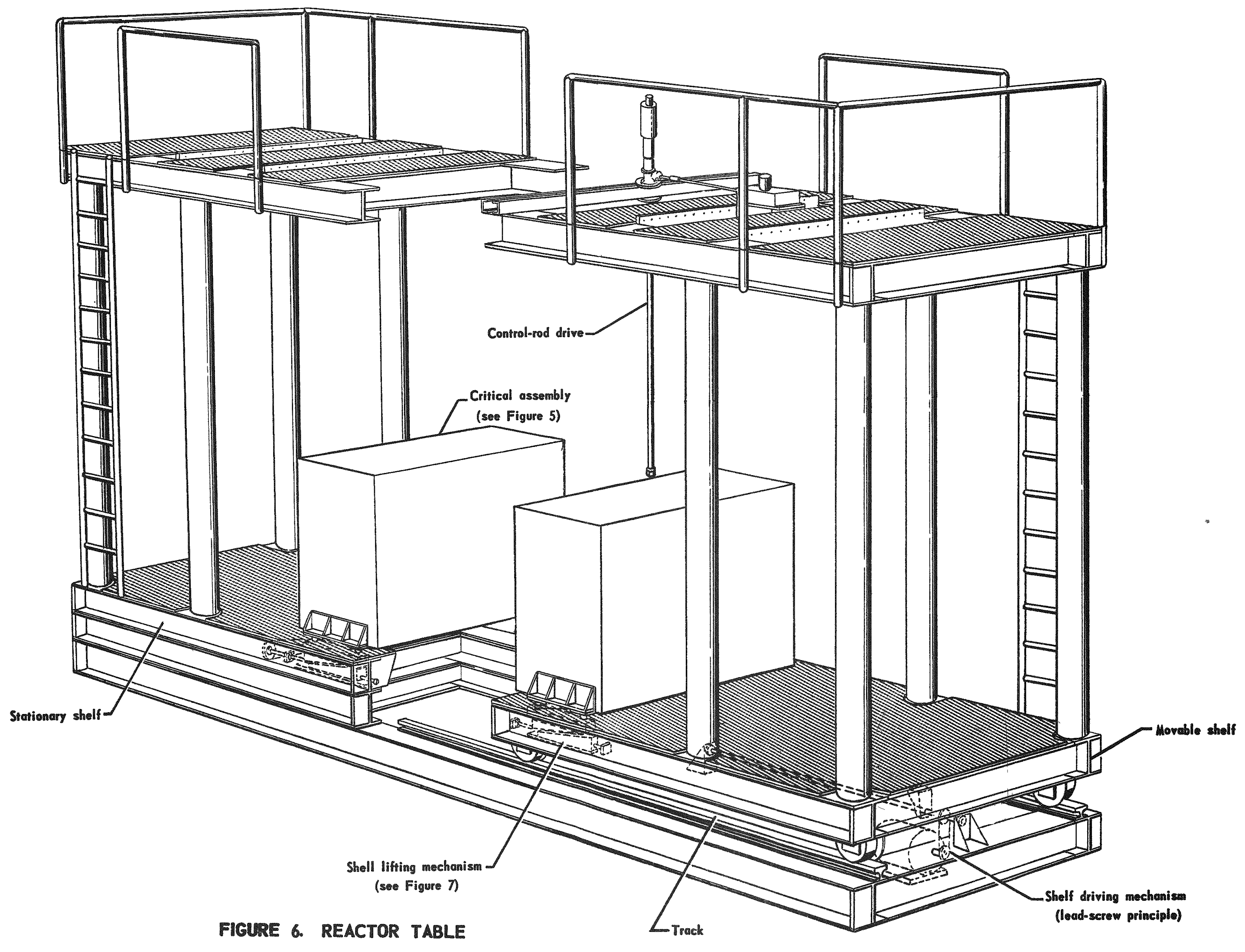

TOAFIDENIIAL

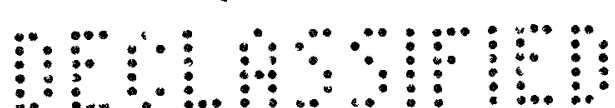

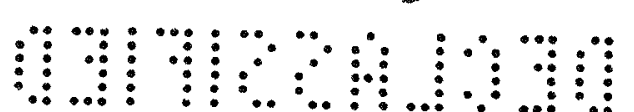


....:

$\because \because$

$\because$

•:

$\vdots \ldots . .$.

$\therefore . .$.

:...:

$\therefore \ldots$...: 


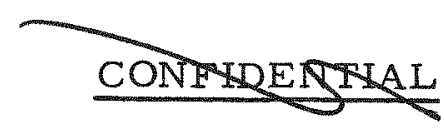

23

Each table half will have available eight safety rods and four drives. A schematic drawing of the table is shown in Figure 6.

A base plate supporting the reflector, but not the core, will be provided to allow the reflector to be moved a small distance (about $1 / 4 \mathrm{in}$.) upward. This upward motion is provided to enable the reflector worth in reactivity to be measured at different heights of the lateral reflector annulus. This plate will be moved by the horizontal motion of a block with a tapered surface moving against an upper block with the opposite taper. Two such devices will be used under each table half. These lifting mechanisms will operate in pairs, one under each table, and will be connected by a tapered rod-and-key-type coupling between two parts of the drive shaft. This connection will also serve as a means of alignment for the entire table assembly. The blocks will be driven by an electric motor. The reflectors base plate will rest on rods extending from the upper block through holes in the deck plate. Figure 7 is a schematic drawing of the lifting device.

\section{Control of Critical Assembly}

The critical assembly will be used to measure the effectiveness of reflector control. Safety will be provided by a group of safety rods, and by separating the reactor tables. A system of electrical controls and interlocks and nuclear and mechanical instrumentation will tell the operator the condition of the reactor at any instant and will prevent unsafe operation of the assembly. A remotely controlled neutron source in each core half will be present for loading measurements, startup, and experimental use.

\section{Mechanical and Electrical Controls}

A total of eight control plates can be made available for each reactor half. Each of the rods has its own rod drive unit but only one power supply is provided. Consequently, the power is available to only one unit at a time. It is currently planned to use two regulating and three safety rods in each half. It is planned that the experiments will go critical with all rods completely withdrawn. This cannot be obtained in all cases exactly but can be nearly attained so as to keep the reactivity small.

The control-rod drive consists of a motor-clutch-type drive unit, Selsyn position indicators, a rack and pinion gear, and a hydraulic shock absorber. The details of the drive unit are shown in Figure 8 and four of the power units and one rack-and-pinion unit is shown mounted on the test stand in Figure 9.

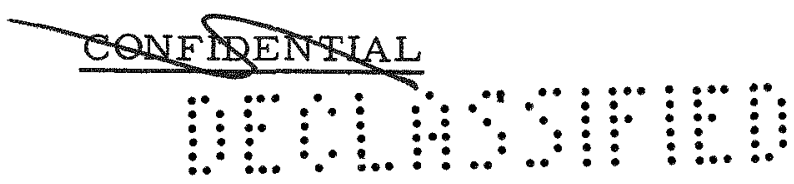




\section{CONIIDEYTIAL}

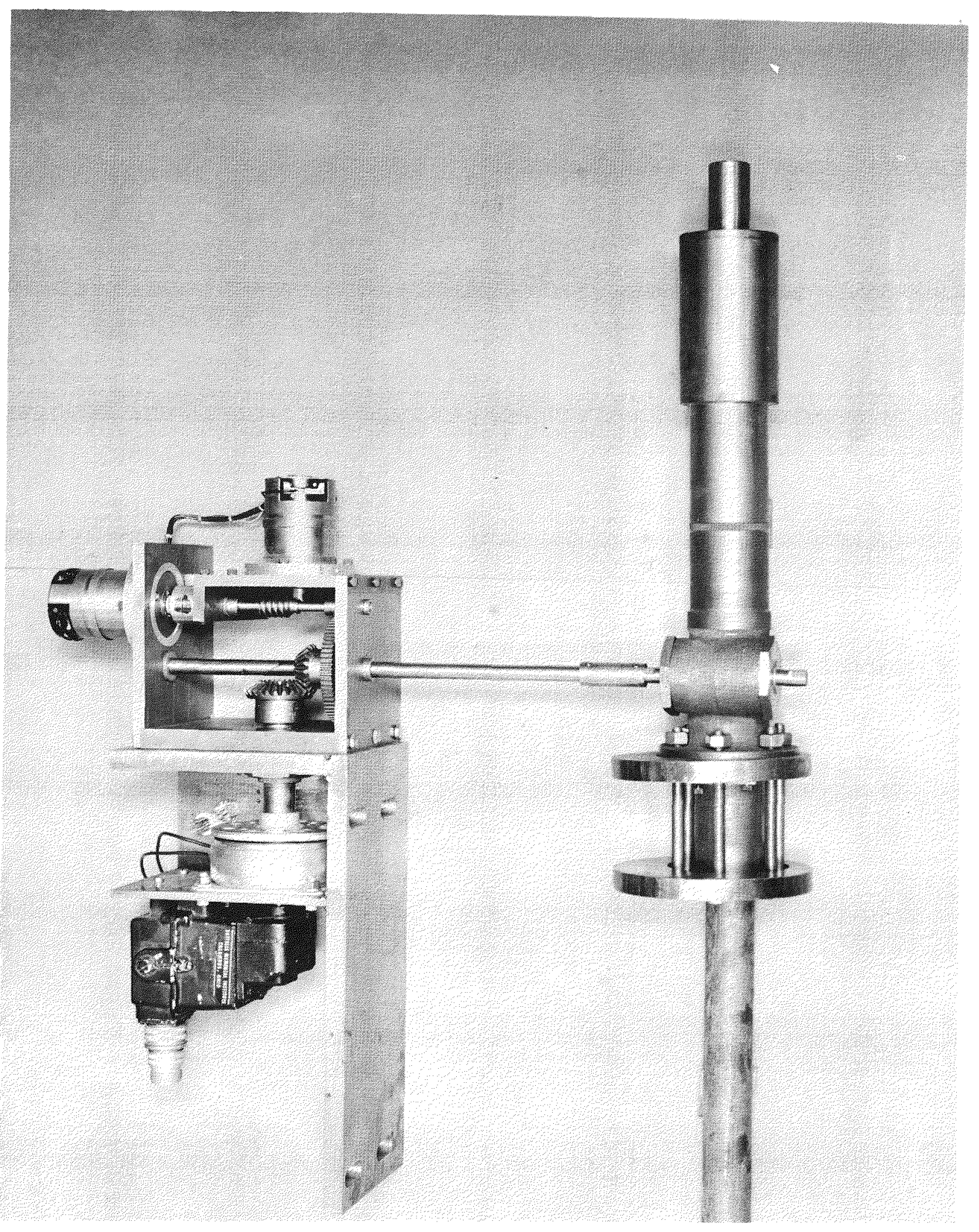

FIGURE 8. ROD-DRIVE UNIT

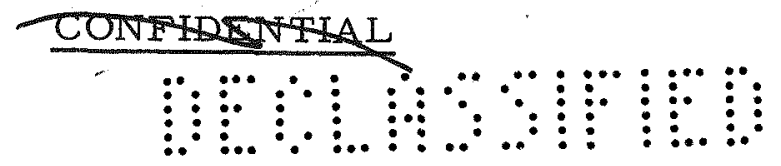


$\therefore \cdots:$

$\therefore \ldots::$

(n.....

$\ldots:$ :

$\because \because$

$\because \because$

$\because \cdots$

:......

$\therefore . .$.

$\vdots \ldots .:$ :

$\therefore: \cdots:$ : e

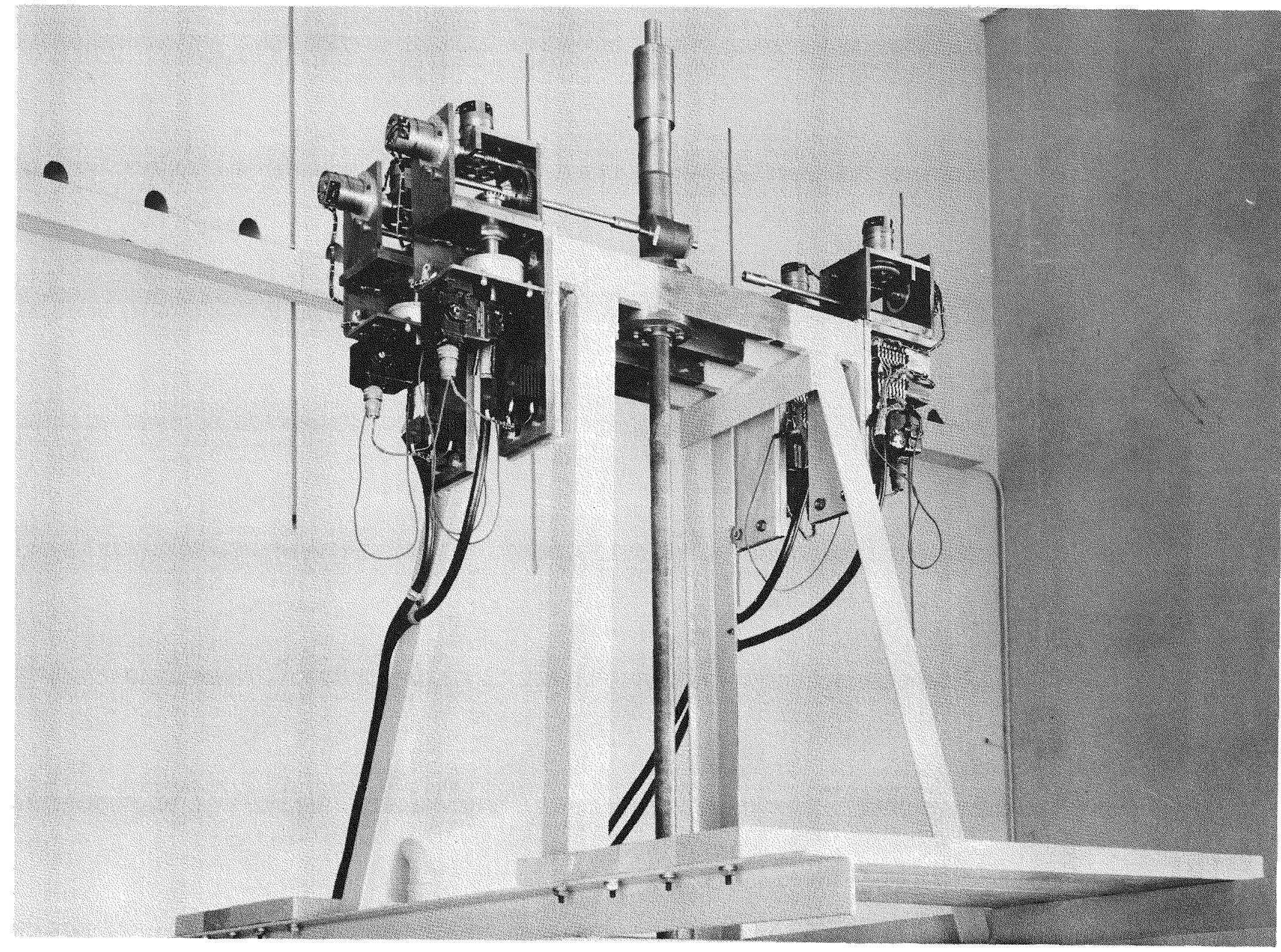

FIGURE 9. ROD-DRIVE ARRANGEMENT 


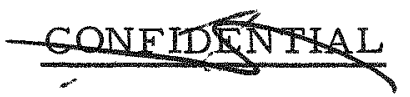

27

The motor-clutch unit contains a reversible variable-speed, $24-v$ dc motor with a gear reducer which permits the motor a maximum speed of 3 rpm. The clutch is a stationary field, electromagnetic type which operates on $90 \mathrm{v}$ dc. It may be disengaged automatically or manually from the reactor control console by removing the power to the magnet.

Following the clutch is a unit containing the Selsyn position indicators and a pair of bevel gears. This whole unit can be pivoted about the drive shaft from the clutch. This arrangement permits locating the motor-clutch unit permanently and turning the Selsyn unit so that the drive shaft to the control rod will reach the rack and pinion unit regardless of its direction from the motor-clutch unit.

One Selsyn is coupled to the drive shaft through a permanent-magnet coupling and a pair of spur gears. This Selsyn makes one revolution for 1 in. of control-rod travel. The other Selsyn is connected to the drive shaft through a worm gear and the spur gears which connect the first Selsyn. This second Selsyn gives one revolution for 50 in. of rod travel. These Selsyns are connected to the rod side of the clutch so that they always indicate the control-rod position rather than the position of the driving motor. The permanent-magnet clutch permits the rod to scram without the fine-reading Selsyn following the drop. The magnet rezeros the fine Selsyn after the drop.

The shaft from the drive unit goes to the rack-and-pinion unit and drives the pinion gear. The rack is fastened to a round steel shaft which goes through the bearings in the rack-and-pinion-unit housing. The control rod is connected to the lower end of this shaft. A hydraulic shock absorber is attached to the upper end. This consists of a piston fastened to the rod and a tapered cylinder filled with oil. This shock absorber strikes the upper face of the rack-and-pinion unit housing to arrest the motion of the steel shaft to which the control rod is attached.

The motor can drive the rod upward or downward at any speed up to 22 in. per min. When the power is cut to the magnetic clutch, the control rod fails under the action of gravity with an acceleration of approximately 0.7 times gravity to scram the reactor.

The rack-and-pinion unit is supported by a pair of steel bars spanning the reactor assembly. The unit is clamped to these bars by a series of bolts passing through a flange in the rack-and-pinion unit housing a clamp ring below the bars. This can be seen clearly in Figure 9. The position of the support bars may be varied and the position of the rod between the bars can be varied over a considerable range. This permits complete freedom in the location of the control rods in the reactor core.

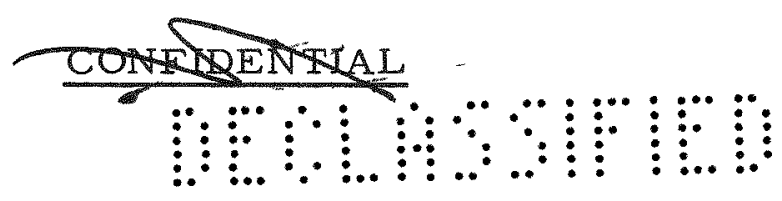




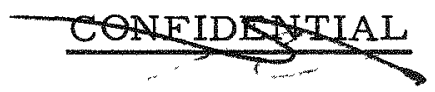

28

Source Drive

There will be a neutron source for startup in each reactor half. This source may be withdrawn into shielded containers during the critical reactor operations. Each source will be in a capsule approximately 0.225 in. in diameter and 1 in. long with a ball on top to permit connecting to the driving unit through a ball-and-socket connection. The sources will enter the reactor from above through tubes which will penetrate into the reactor core about 6 in.

The source will be pushed into the core and pulled out by means of a flexible cable. This cable will have a spirally wound wire on it and will be driven by a gear so that the gear and cable have the appearance of a worm and worm gear. However, they will act like a rack-and-pinion unit. The power will be from a $d-c$ geared motor. Limit switches operating off the end of the cable will prevent overdriving of the source in either direction. An interlock switch which will be operated over the last 6 in. of travel will permit the operation of the rod drive and table drive if the flux is not above a prescribed level.

Table Drive

Figure 10 shows the connections for the thyratron-controlled tabledrive motor. Two feedback loops are used to regulate the speed and the torque of the motor. The triode amplifier monitors the armature current through the l-ohm resistor and serves to maintain torque constant at the value for rated motor speed. Motor speed is monitored by the tachometer effect of the motor in generating a back emf. This back emf is applied to the cathodes of the thyratron tubes and results in a bias voltage on the thyratron grids.

The bias voltage on the thyratron grids is also controlled by the 1 megohm potentiometer. This is used to set the speed at which the motor is to run. Failure of the 6SF 5 triode will result in an increase of current through the potentiometer and a subsequent increase in motor speed. This is protected against through the power-supply interlock circuit. The $\mathrm{K}-1$ relay allows the circuit to continue in operation in the event of a legitimate change in armature current.

The back emf depends on the shunt field strength. If the 83 rectifier fails, there will be a big drop in back emf and the motor would have to speed up considerably to compensate for this loss. However, if this tube fails, the thyratron grid voltage goes negative and the tubes will not conduct. This, of course, will stop the motor.

The motor reversing circuit is not shown on this diagram. It will be actuated manually at the console, or by a scram signal. Also, the 1 -megohm potentiometer will be replaced by three fixed resistances corresponding to

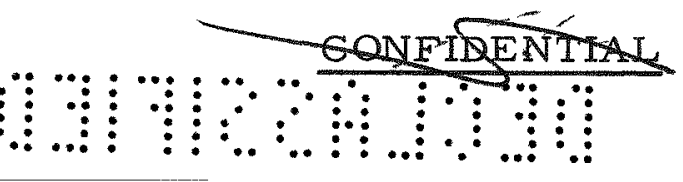



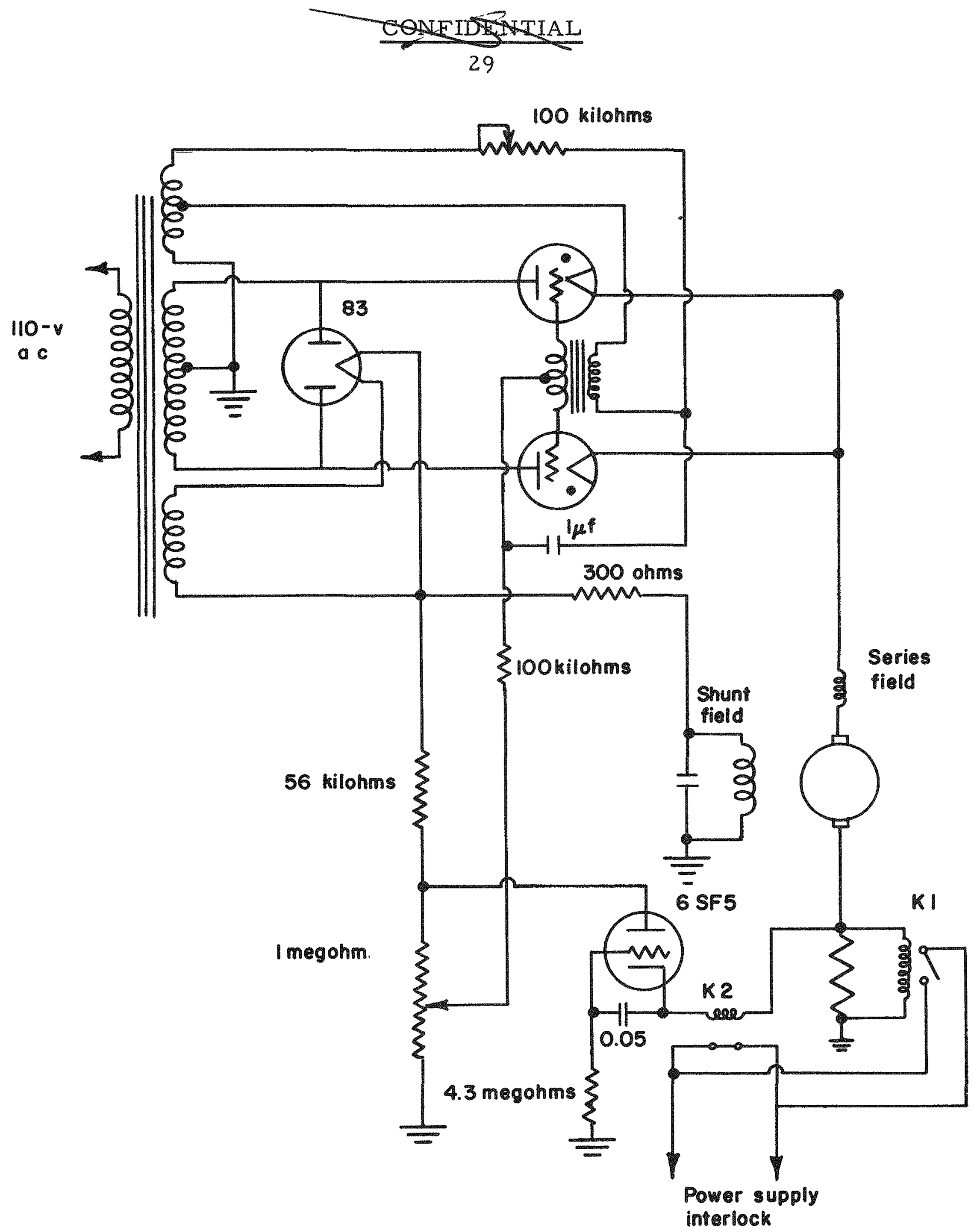

A18322

FIGURE 10. SIMPLIFIED MOTOR-CONTROL CIRCUIT FOR TABLE DRIVE

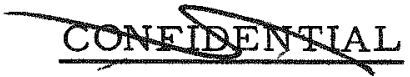

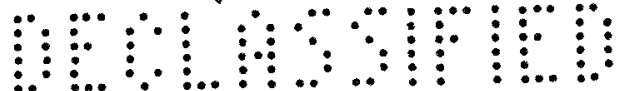




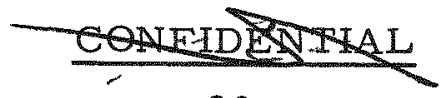

30

the three desired table speeds. These resistors will be cut in and out by limit switches actuated by the table.

The interlock and "scram" circuits are entirely switch and relay circuits (no electronics). The circuits are designed to actuate on the opening of switches and relays. Relays are fail-safe and are connected so they actuate on removal of power from coils. In circuits containing large inductive loads, precautions against arcing at relay contacts have been taken. These precautions include the use of double-break relay contacts and the use of selenium rectifiers to short-circuit the inductive emf.

The functions of the interlock and scram circuit are outlined in Figure 11 .

Control and Research Instrumentation

The bulk of the reactor instrumentation is contained in a console-type control panel in the control room. This console is designed to mount instruments with standard 19-in. relay-rack panels. Each panel is wired into the system through barrier terminal strips on the unit and fanning strips on the connecting cables. This facilitates removal of any instrument or unit for modification or repairs and also allows access to the terminals for testing and trouble shooting. Where low-level signals require it, separate cables of shielded audio leads or coaxial cable are used. Signal cables are grounded at the instrument end only.

Meters and controls for the operation of the critical assembly are located in a position in front of the operator. Above this, on an inwardsloping panel, are located the rod-position indicators. Meter-relay monitors, recorders, and the closed-circuit television screen are located around the periphery of the console.

The nuclear instrumentation is shown by the block diagram, Figure 12 . Three compensated ion chambers are used as neutron detectors and monitors. One chamber is connected to a linear vibrating-reed-type electrometer on the console. Negative feedback to the input lowers the input impedance and permits the use of a long cable. The output of this instrument is used for the visual indication of neutron flux. This output is also recorded on a circular-chart recorder and is monitored by a meter relay for the safety circuits. The other ion chambers are connected to logarithmic electrometers in the assembly room. The output of these electrometers is connected directly to the safety circuits and also to differentiating circuits on the console to provide visual period indications and to actuate the safety circuits. On one of the se channels the ion chamber will not be compensated, since it will be used entirely as a safety circuit. A strip-chart recorder

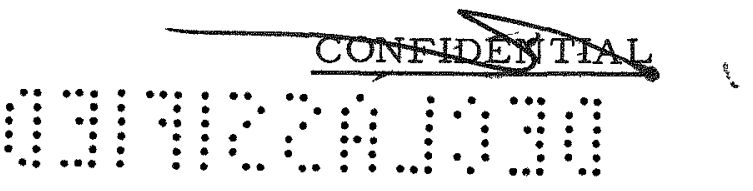




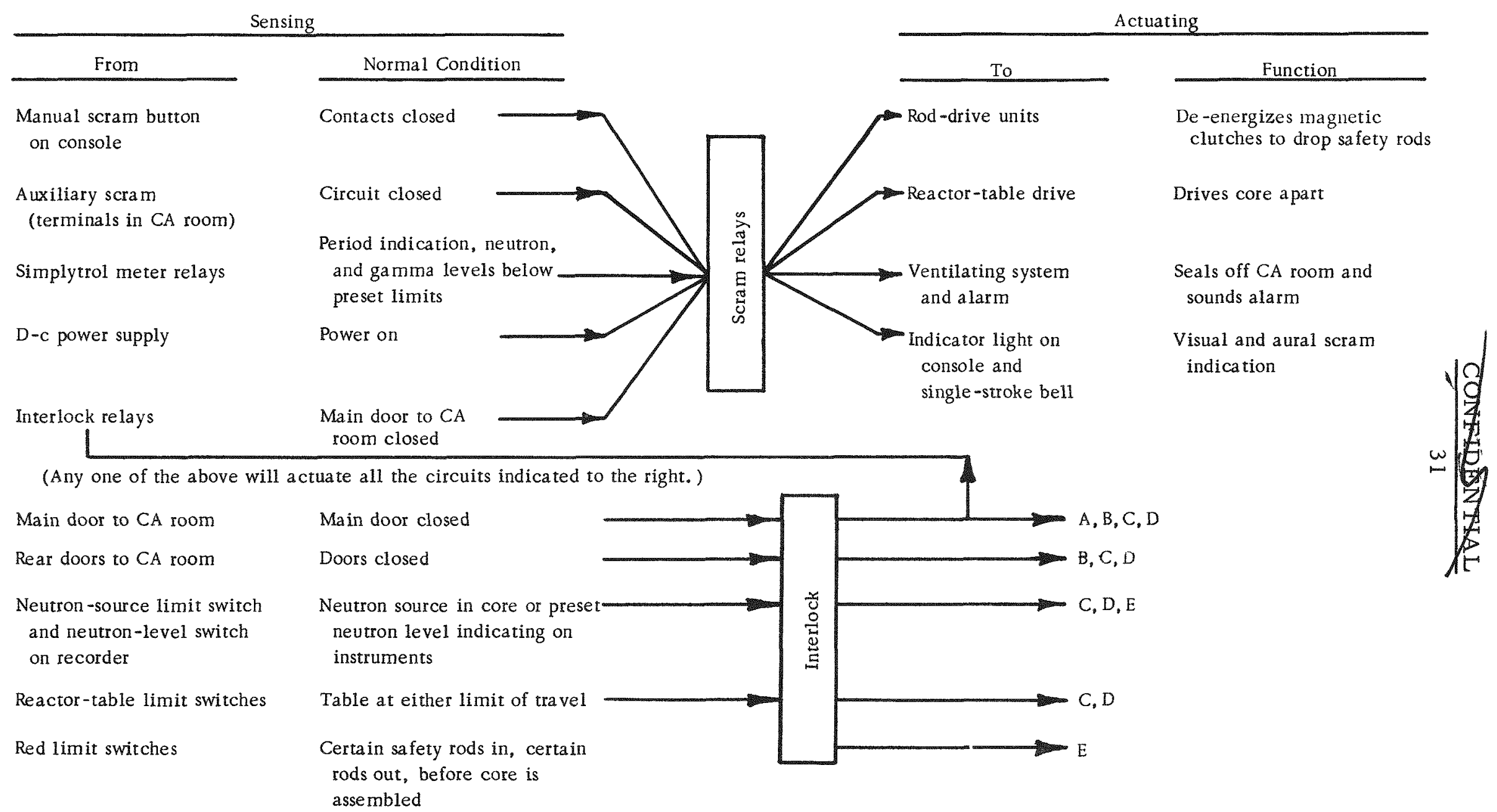

(A) To scram relay causing a scram if door is opened during reactor operation. (B) To warning light on console to indicate door open at any time. (C) To interlock light on console to indicate open interlock circuit. (D) To interlock relays to prevent withdrawal of control rods. (E) To interlock relays to prevent assembly of two halves of core. 


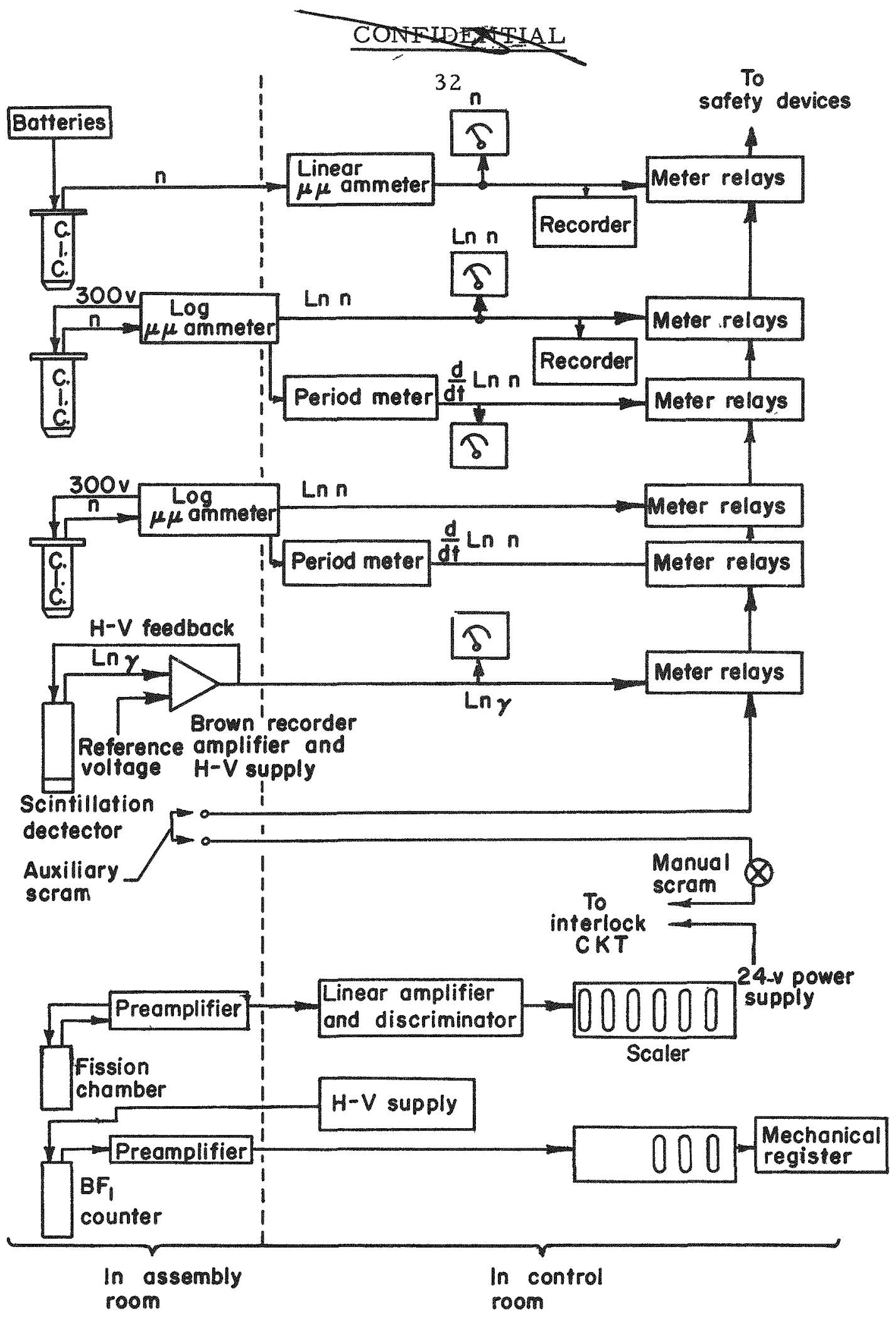

41938

FIGURE 12. BLOCK DIAGRAM OF REACTOR INSTRUMENTATION 


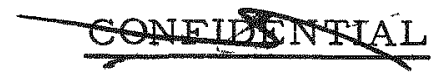

33

records the log level. The slope of the curve on this chart will be a record of the period.

A six-decade wide-range gamma channel consisting of a scintillation detector connected to a servo amplifier gives a log indication of gamma flux and is also connected into the safety circuits.

In addition to the safety or control circuits, two research circuits are provided. These channels provide accurate low-level information for startup and accurate neutron indications at operating levels, when required. They can also be used to provide an aural indication of power level and to provide additional visual indication of power level. Both of these channels use pulsecounting instruments and are independent of the safety instrumentation. One of the se is a fission-chamber channel consisting of a linear amplifier and a scaler with provisions for a digital recorder. The fission chamber and preamplifier are located in the assembly room. The other channel uses a boron trifluoride counter as detector. It consists of a scaler with a built-in amplifier and high-voltage supply. The counter and its preamplifier are located in the as sembly room.

Rod and source positions are indicated by Selsyn indicators. Two sets of Selsyns are utilized for each control-rod drive to obtain the required accuracy.

Two sets of Selsyns will also be used to indicate table position. The se will be geared to the table lead screw to indicate the position to the nearest 0.01 in. over its entire travel. The final closing gap will be measured to 0.001 in. at three points by means of linear differential transformers. Travel limit lights will also serve as a check on the indicators.

A closed-circuit television with a 17-in. screen is located on the console to provide remote viewing of the critical-assembly experiment.

Actuating controls on the console are level switches for operation of rod drives, table drives, and neutron-source drives. A selector switch is used to select the rods to be manipulated. Only enough power is available to operate one rod-drive motor at a time. A manual scram button on the control panel is provided for emergency shutdown. Two terminals in the assembly room are wired into the circuit of the scram button so that experimental setups may be wired into the safety circuit if needed. This is indicated as an auxiliary scram in Figure 12.

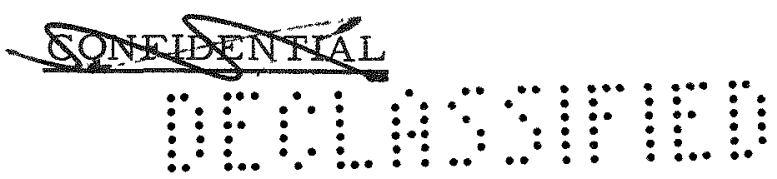




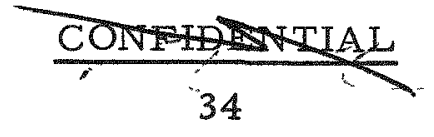

Plan of Operation and Types of Experiments

The experimental program is planned to investigate most thoroughly the novel features of the reflector control system. The most important results will be (1) the reactivity worth of the reflector as a function of position, (2) the total worth of the reflector, and (3) the effect of the changing reflector position on the flux and power distribution. Other experiments will be done to learn more about the reactor parameters and to optimize the design of a reflector-controlled reactor.

The basic experiments which will yield the desired data are described below along with the plan of operation for each basic experiment.

Approach to Critical

Each approach to critical will follow a set procedure which is described below and which to a large extent is enforced by the interlock system. The initial approach, which will be used after any modification in the reactor or instrumentation, will be made stepwise with counts being taken on scalers as well as data being taken on all indicating instruments. Once the critical state of a given reactor configuration has been determined, subsequent approaches to critical for that assembly may be made by continuous operation of the controls and by following the neutron levels on the instruments and the recorders.

Each approach to critical will be preceded by an operational check out, during which each radiation detector will be checked and calibrated. The scram circuits will be checked and each scram mechanism will be operated. The interlocks will be checked by attempting operation contrary to their design purposes. Following this a visual check will be made of the facility and the room. The door to the assembly room will be closed and a standard check-out form will be signed by the person making the check.

The sources will then be inserted and one control rod in each reactor half will be raised to its full height. One rod in each half will remain fully inserted. Any remaining rods may be positioned at any location at the option of the operator.

The table will then be moved in steps, with counts taken on the research channels and readings taken on the indicating safety channels at each step. These steps will initially be approximately $1 \mathrm{ft}$ and will decrease to about $1 / 2$ in. as the tables near closing. Counts and instrument readings will be taken again with the table in the closed position. The control rods will then be withdrawn in steps estimated to give 0.15 per cent reactivity change per step. Counts and detector readings will be recorded after each step.

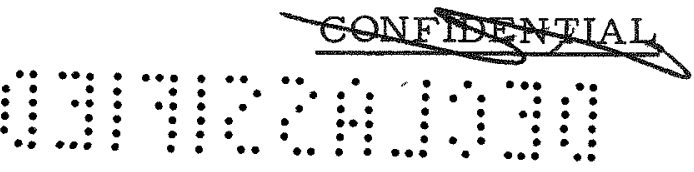




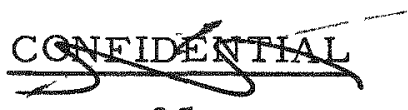

35

During the course of this approach to critical, the inverse count $r$ ate will be plotted against the position of the table, and later against the position of the control rods. This plot will be extrapolated to zero to predict the critical condition. This extrapolation will be revised after each new count.

When the reactor neutron level $r$ ises into the operating $r$ ange, the sources will be withdrawn in steps and the control rods adjusted to keep the power at a nearly constant level. When both sources are fully out and the power remains level, the reactor is critical.

Calculations to determine the critical mass of new reactor configurations will be made prior to any experimental work. Then the new reactor configuration will be built up initially with considerably less fuel than the calculated value. Additional fuel loadings will be made in steps and the critical procedure followed in each case. This will minimize the possibility of incorporating too large an excess reactivity into the core.

Control-Rod Calibrations

Generally, changes in the reactor will be measured in units of reactivity. These measurements may be made by comparing the changes to the change in position of a calibrated control rod. For this reason the calibration of control rods becomes a basic measurement.

The basic procedure for calibrating a rod is to establish the rod position for criticality and then move the rod upward a short measured distance. Following this the neutron level increases exponentially. This rate of increase can be measured and the value of the rod motion in terms of reactivity established by using the inhour relation. Another means of calibrating the control rod is the rod-oscillation method. The neutron-level oscillations, resulting from the small amplitude oscillations of the rod, are measured and related to reactivity. Alternatively, the rod can be dropped from its critical position and the transient change in neutron level measured. All three procedures are established procedures used at one or more AEC installations and do not require development work.

\section{Other Reactor Experiments}

The reactivity worth of the reflector may be measured by comparing it to the equivalent worth of a calibrated control rod. However, the reflector can be moved 1/4 in. independently and may be treated as a control rod. Its worth for this small motion can be determined by measuring the reactor period which its motion can produce or by oscillating the reflector at very low frequencies.

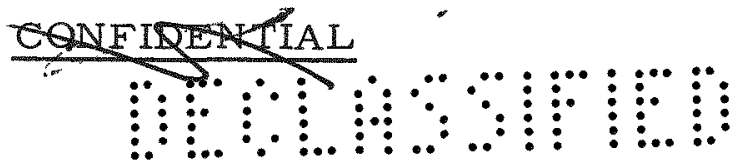




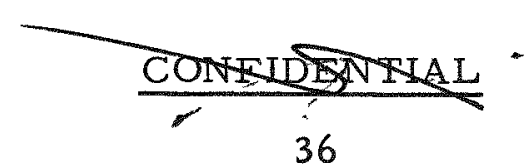

Flux and power measurements will be made by irradiating and counting the induced activity of various materials such as gold, indium, and manganese. These materials will be irradiated both bare and cadmium covered. Power measurements may also be made by counting the fissionproduct activity in irradiated uranium or by counting the fission-product activity in aluminum catcher foils which will be exposed next to uranium plates.

These experiments may be repeated for different core configurations, for different control-rod arrangements, and for different reflector conditions.

\section{Assembling Operations}

The assembly operations are considered as part of the normal operations since it is anticipated that several different loadings will be required during the course of the planned experiments. Therefore, it will be necessary to adopt procedures and controls which will insure that there are no criticality hazards during the course of construction work.

The various procedures which will be used during the construction phases of the program are described in detail in a communication to the Chicago Operations Office. These procedures will not be repeated here in detail. The general features which are being adopted to insure safety are: (1) the amount of uranium -235 which will be handled at any one time will be limited to $350 \mathrm{~g}$ in one batch or $700 \mathrm{~g}$ at one operational location, with the exception of the reactor assembly itself; (2) the location of the uranium and the amount assembled at any one point will be carefully controlled by having flow and balance records at each point at which the material is handled; and (3) a supervisor will be appointed who will have the responsibility for each procedure being carried out.

In addition to these precautions, the multiplication of the reactor will be measured during the course of its construction. This will be done by measuring the neutron level continuously if the neutron intensity in the vicinity of the core does not present a biological hazard to the personnel. If the neutron intensity is too high, the multiplication will be measured after the addition of each six fuel elements and at more frequent intervals if the supervisor or the man making the counts requests it. This information will be continuously plotted and evaluated.

\section{Precritical Operation Check-Out}

Prior to each day's reactor operation, and more often if the supervisor should request it, a complete check will be made of the instrumentation and

\section{CONFHDENTAL}


safety mechanisms of the reactor. Each radiation detector will be checked for calibration. Each scram circuit will be checked and each scram mechanism will be operated. The interlocks will be checked by attempting operation contrary to their design purpose. Following this, a visual check will be made of the facility and the room, the door to the assembly room will be closed, and the check-out form will be signed by the person making the check.

Processing and Disposal of Radioactive Materials and Solutions

The only processing of material planned for the critical-assembly building is the preparation of small uranium foils. Any other processing will be done in the uranium area at the main Battelle laboratories in Columbus, which are equipped and experienced in all phases of material handling.

Only solid materials are planned for use in this critical-assembly program. Thus, there will be no solution-disposal problem.

Since all experiments will be done at low power $(0.01$ to $10 \mathrm{w})$ there will be no high-level induced activities. The possibility of fission-product contamination will be examined by taking periodic air samples and smear tests.

\section{Limitations}

The maximum reactor power level anticipated is about $20 \mathrm{w}$. Since the normal operating level will be about $1 \mathrm{w}$ (or less) the power will be limited, at most times, to a maximum of 5 to $10 \mathrm{w}$. The $20-\mathrm{w}$ level is a maximum estimate based on the necessary flux level to obtain some of the foil activations. For normal operation, the minimum allowable period will be 5 to $8 \mathrm{sec}$. The rate of increase of $\Delta \mathrm{k} / \mathrm{k}$ will be limited by design to a calculated value of 0.04 per cent per sec. This affects primarily rod-worth and rod-withdrawal rates, reflector motion, and final table-closure $x$ ates.

\section{Special Characteristics of the Critical Assembly}

The characteristics associated with the safety of this critical experiment cannot be completely specified because the physical condition of the core is not fixed. Values of $\tau, L^{2}, \Sigma_{\text {a }}$, etc., will be varied, as will reflector height and void distribution. The core characteristics are particularly difficult to predict when the void distribution is not uniform, and, 


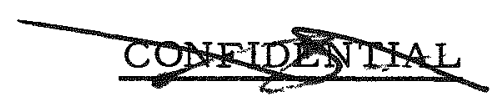

38

indeed, an indication of the effect of void distribution on certain reactor parameters is one of the objects of this investigation. In estimating certain parameters such as neutron lifetime, temperature coefficient, approximate effect of reflector height, etc., uniform void distribution was assumed, and, where possible, worst conditions were estimated.

The critical assembly will be a thermal reactor, fueled with fully enriched uranium, and moderated with polyethylene to simulate water. The core will be surrounded by a polyethylene reflector. Pertinent physical properties $(1) *$ of polyethylene are:

$\begin{array}{ll}\text { Specific gravity } & =0.92 \\ \text { Thermal conductivity } & =2.96 \mathrm{Btu} /(\mathrm{hr})\left(\mathrm{ft}^{2}\right)(\mathrm{F} / \mathrm{in} .) \\ \text { Specific heat } & =0.53 \mathrm{Btu} /(1 \mathrm{~b})(\mathrm{F}) \\ \begin{array}{l}\text { Linear coefficient } \\ \text { of expansion }\end{array} & =18 \times 10^{-5} \text { per } \mathrm{C}\end{array}$

Softening temperature $=110-120 \mathrm{C}$

Yield point $\quad=1250 \mathrm{psi}$

Modulus of elasticity $=18,000 \mathrm{psi}$

The total amount of uranium available for this experiment is $10 \mathrm{~kg}$ of foil. The minimum critical mass for the fully reflected reactor, with a polyethylene density simulating that of room-temperature water, is estimated to be 2.7 to $3 \mathrm{~kg}$. The critical mass for the condition of maximum voids and a 6-in. lateral reflector gap is difficult to make because of the unknown effect of void distribution. Estimates indicate a requirement of 6 to $8 \mathrm{~kg}$.

The temperature coefficient of the polyethylene was estimated for the no void-fully reflected condition, and for maximum void-6 in. reflector gap condition. These values are $-0.36 \times 10^{-5} \Delta \mathrm{k} / \mathrm{k}$ per $\mathrm{C}$ and $-1 \times 10^{-4} \Delta \mathrm{k} / \mathrm{k}$ per $C$, respectively. The moderator was assumed to expand in one direction only in the se estimates. The effect of metal temperature on reactivity should be relatively small in a fully enriched thermal reactor. To get an indication of this effect, it was assumed that only the broadening of lowest energy resonance peak of uranium-235 would affect the criticality. An estimate of the increase in this resonance absorption with temperature was made based on curves given in The Reactor Handbook. (2) If the absorptions at this energy level are assumed to have the same importance as thermal

References at end of text.

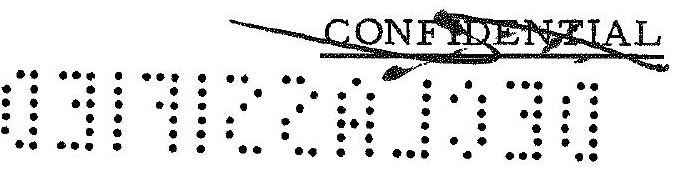


absorptions, the resultant estimated temperature coefficient is about $4 \mathrm{x}$ $10^{-7} \Delta \mathrm{k} / \mathrm{k}$ per $\mathrm{C}$.

The neutron lifetime in this core was estimated assuming only the diffusion time of thermal neutrons to be important and assuming the maximum possible fuel loading $(10 \mathrm{~kg})$ and the maximum possible average absorption cross section in the core. These assumptions gave a lifetime of $3.6 \times 10^{-5}$ sec.

The effect of a 6-in. lateral reflector gap on criticality has been estimated, for the case of uniform void distribution in the core, by several different methods. (3) The results of these calculations indicate a value of $\Delta \mathrm{k} / \mathrm{k}$ of about 10 per cent. On the basis of this estimate, a reflector movement of $1 / 4 \mathrm{in}$. obtained in $6 \mathrm{sec}$ will be within the design limit of 0.04 per cent $\Delta \mathrm{k} / \mathrm{k}$ per sec.

\section{Safety Mechanisms}

\section{Control and Safety Rods}

The principal safety device in the system will be poison safety plates. These plates will contain cadmium over a minimum length of $2 \mathrm{ft}$, and will have a width of about $4-1 / 2$ in.

The rod-withdrawal rate of $22 \mathrm{in.}$ per min and the design limitation of a $\Delta \mathrm{k} / \mathrm{k}$ per sec of 0.04 per cent determine the maximum allowable worth of any control element. This value is estimated to be 1.3 per cent. Twogroup calculations combined with first-order one-group perturbation theory were made on a reference reactor to get an estimate of the $\Delta \mathrm{k} / \mathrm{k}$ worth of the safety plates. Since the core will be operated under various conditions, parameters determining $\Delta \mathrm{k} / \mathrm{k}$ (slowing-down length and diffusion length) are not fixed, so upper and lower limits on $\Delta \mathrm{k} / \mathrm{k}$ were estimated. In all calculations, the control plates were assumed black to thermal neutrons. The results are tabulated below:

\begin{tabular}{lllll} 
& \multicolumn{4}{c}{ Position of $\operatorname{Rod}(\mathrm{a})$} \\
\cline { 2 - 3 }$\frac{\mathrm{k}}{\mathrm{k}}$ maximum & $\frac{1}{0.027}$ & 0.018 & 0.006 & 0.009 \\
$\frac{\Delta \mathrm{k}}{\mathrm{k}}$ minimum & 0.016 & 0.010 & 0.003 & 0.005
\end{tabular}

(a) Position $1-X=0, Y=0$ (where the origin is at the intersection of the vertical axis of the core and the table support)

Position $2-X=12.5 \mathrm{~cm}_{0} Y=0$

Position $3-X=12.5 \mathrm{~cm}, Y=25 \mathrm{~cm}$

Position $4-X=4.1 \mathrm{~cm}, Y=25 \mathrm{~cm}$.

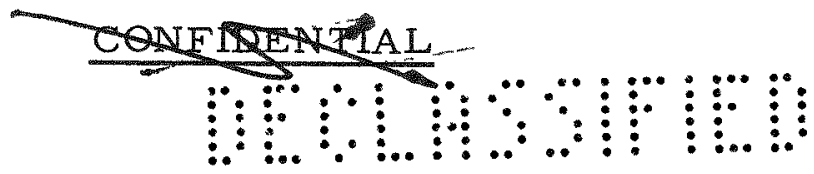




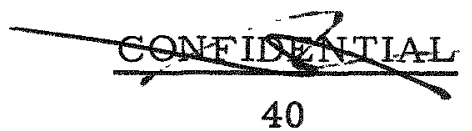

These calculations determine control-plate positions such that $\Delta \mathrm{k} / \mathrm{k}$ per sec is no larger than 0.04 per cent $\left(\frac{\Delta \mathrm{k}}{\mathrm{k}} \leqq 1.3\right.$ per cent $)$.

The safety plates fall by gravity, but to estimate the time of fall it is necessary to assume some frictional resistance. An assumption that the accelerating force is $0.7 \mathrm{~g}$ gives the time to fall $2 \mathrm{ft}$ as $0.42 \mathrm{sec}$.

Table Separation

The tables can be separated at the rate of $25 \mathrm{in.}$ per min at any time. The drive unit is such that the motion can be changed from any for ward speed to full reverse speed through a control on the console. This reversal will occur automatically on any scram except one due to power loss. At present, no device is incorporated in the design to separate the tables remotely in case of a power failure. The reactor would be automatically scrammed in this case and the tables could be manually separated. Figure 13 shows the calculated reactivity loss as a function of table separation.

Electrical Interlocks

Electrical interlocks have been included to prevent the following:

(1) Entering the assembly room when the reactor is operating or in an operating condition

(2) Startup without a neutron source in each reactor half

(3) Reaching critical by moving tables together (must go critical with rods, which is a more quickly reversible process).

(4) Moving tables together without safety rods cocked

(5) Moving rods and table at the same time.

Instrumentation

The safety instrumentation includes four detectors with one level scram originating with each of the four and a period scram from two of the four. All instruments are d-c devices, minimizing the possibility of scram failure from overloading.

With the exception of the contact meters originating the scrams, all scram relays are held in by electrical power, causing a scram on the receipt of a scram signal or power failure. Each scram circuit has two contact meters in parallel so that a single failure would not prevent a scram

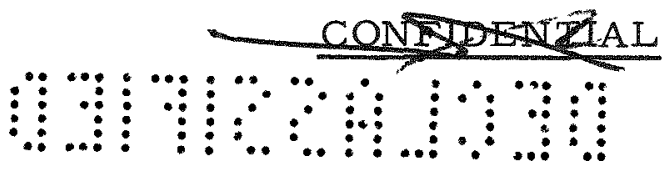




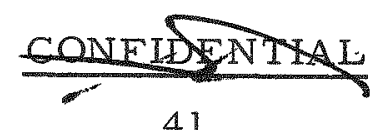

41

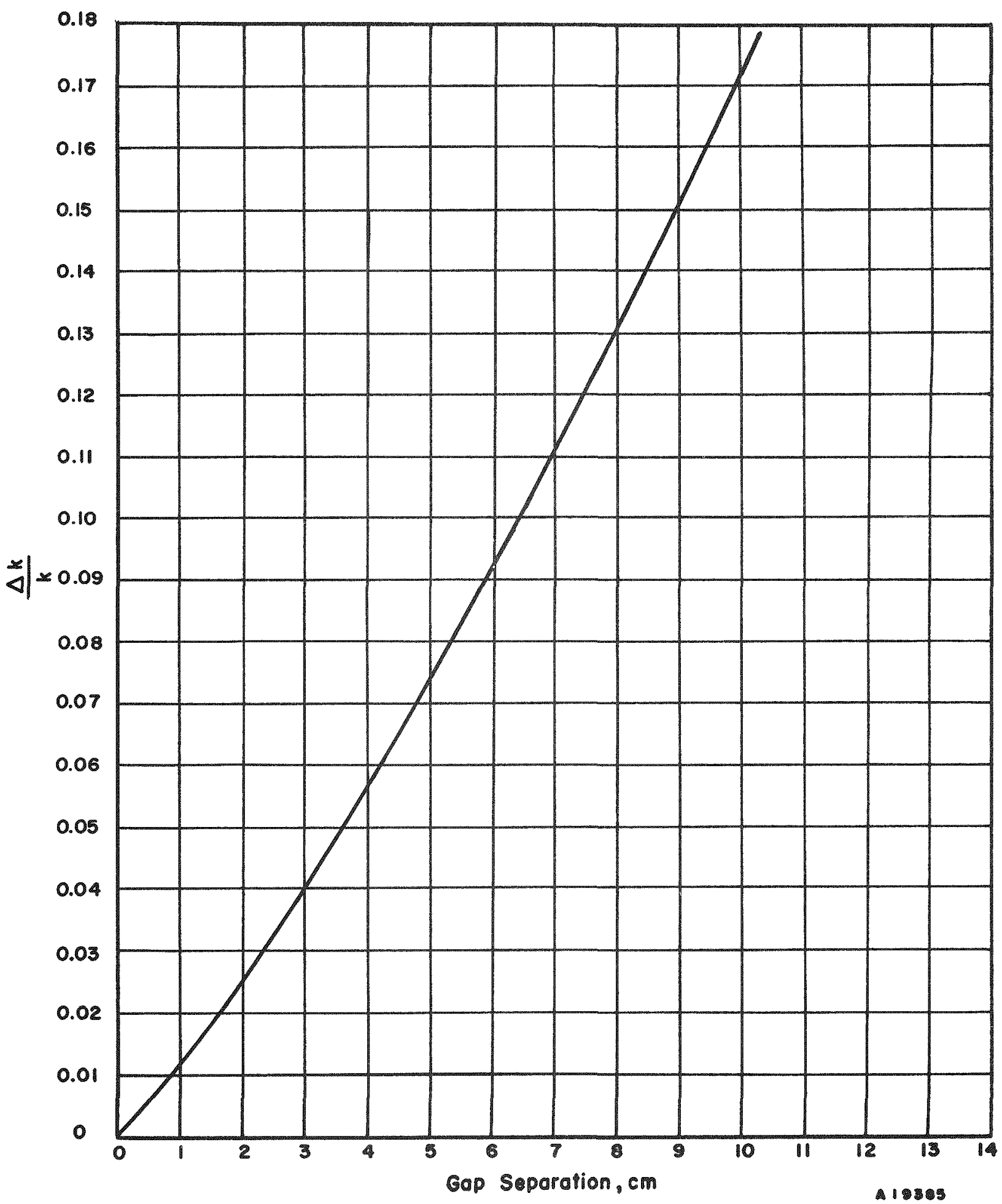

FIGURE 13. REACTIVITY LOSS VERSUS GAP SEPARATION

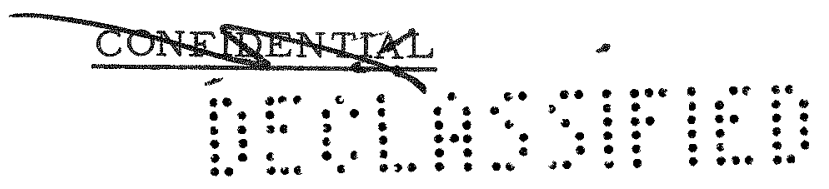




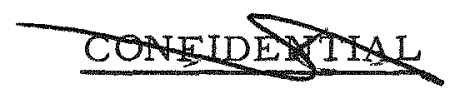

42

from taking place in that circuit. A double failure in a single scram circuit would still leave five other scram circuits operative.

The instrumentation also includes two pulse-counting channels to give more accurate data when needed, particularly for reactor startup. One of the se channels includes a mechanical register which will give the operator an indication of power changes.

\section{MAKE-UP OF SURROUNDING AREA}

The location of the site and a brief description of the geography of the region was given in a previous section. The sections below discuss other features of the area with emphasis on factors which may be related to the operation of the critical facility.

\section{Pouplation Distribution}

The proposed site is located about 15 miles west of the center of Columbus, Ohio, in a sparsely populated area. A. 10-mile-radius circle enclosing the site includes a small portion of Columbus having a population of about 20,000 people. The only other significant population center near the site is West Jefferson, Ohio, located about 2 miles from the site, with a 1953 population of 2500 .

The population distribution at various radii from the site was obtained, for the most part, from the Chamber of Commerce 1954 statistics and the State-Wide Highway Planning Survey, 1953. The distribution of population at various distances from the site is shown in Table 1.

TABLE 1. POPULATION DISTRIBUTION WITHIN VARIOUS DISTANCES FROM SITE

\begin{tabular}{cr}
\hline Distance Radius & Population \\
\hline 1500 feet & 0 \\
2500 feet & 0 \\
1 mile & 60 \\
2 miles & 1,150 \\
5 miles & 5,100 \\
10 miles & 43,000 \\
\hline
\end{tabular}

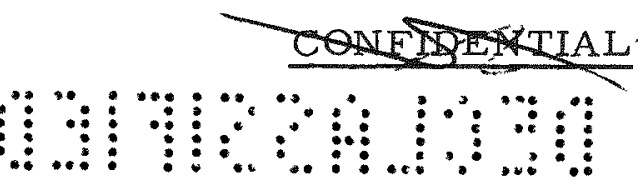


Industry Adjacent to the Site

Within the 10-mile circle are located 12 industries. Ten of the se employ less than 100 people while the Westinghouse Electric Corporation and the General Motors Corporation, both 8 miles from the site, employ about 4000 and 3931 , respectively. Closest to the site are two small industries in West Jefferson which employ less than 100. The industries and information pertinent thereto are tabulated in Table 2.

At a distance of 8 miles from the site is located a new housing project, Lincoln Village. Opened for settlement in July, 1954, the village has a present population of approximately 400 families. Future expansion is to include several industries; the information regarding these industries has not yet been released.

\section{Seismology}

In determining the earthquake probability of a given area, all that can be done is to examine the earthquake history of that vicinity and then conjecture that future earthquakes are more likely to occur in places where there have been previous ones.

Several areas in western Ohio have suffered minor earthquake damage. There is no record of earthquakes having occurred in West Jefferson, Ohio, and immediate vicinity. The nearest seismic activity in recent years was recorded in 1937 in the Anna, Ohio, proximity, which is over 50 miles from the proposed reactor site.

The information on western Ohio earthquakes was obtained from Reverend V. C. Stechschulte, Xavier University, Cincinnati, Ohio, and from the U. S. Coast and Geodetic Survey. Letters from these two sources are included in Appendix A.

\section{Climatology}

The climate in the Columbus area is definitely temperate and continental in character. The normal mean daily temperature for June, July, and August is $73.3 \mathrm{~F}$, although 90 degrees or higher is expected about 20 times per year. During the months of December, January, and February, the normal seasonal temperature is $31.2 \mathrm{~F}$ with 3 subzero nights per winter average.

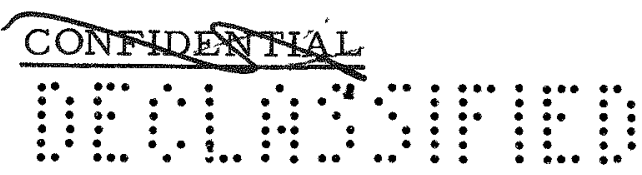




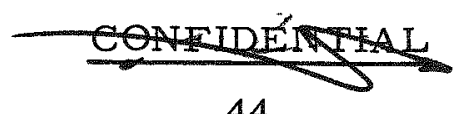

44

TABLE 2. INDUSTRIES WITHIN A 10-MILE RADIUS OF PROPOSED REACTOR-FACILITY SITE

\begin{tabular}{|c|c|c|c|}
\hline Industry & Products & $\begin{array}{l}\text { Number of } \\
\text { Employees }(\mathrm{a})\end{array}$ & $\begin{array}{c}\text { Distance } \\
\text { From } \\
\text { Site }\end{array}$ \\
\hline $\begin{array}{l}\text { Terndstedt, Columbus } \\
\text { Division, GMC }\end{array}$ & Auto parts & 3931 & 8 miles \\
\hline $\begin{array}{l}\text { Westinghouse Electric } \\
\text { Corporation }\end{array}$ & Refrigerators, appliances & $\sim 4000$ & 8 miles \\
\hline $\begin{array}{l}\text { Stokely's Canning } \\
\text { Company }(\mathrm{b})\end{array}$ & Canned sweet corn & $75-85$ & 2 miles \\
\hline $\begin{array}{l}\text { Hartley Printing and } \\
\text { Publishing Company }\end{array}$ & Printing and publishing & 27 & 10 miles \\
\hline $\begin{array}{l}\text { Columbus General } \\
\text { Machine, Inc. }\end{array}$ & Dies, tools, fixtures & 12 & 10 miles \\
\hline $\begin{array}{l}\text { H. J. Upperman and } \\
\text { Sons }\end{array}$ & Lumber & 12 & 9 miles \\
\hline $\begin{array}{l}\text { Columbus Stationery } \\
\text { Company }\end{array}$ & Stationery & Less than 10 & 9 miles \\
\hline $\begin{array}{l}\text { Five Manufacturing } \\
\text { Company }\end{array}$ & Farm wagon unloaders & Less than 10 & 9 miles \\
\hline $\begin{array}{l}\text { Georgiton Candy and } \\
\text { Ice Cream Company }\end{array}$ & Ice cream, candy & Less than 10 & 10 miles \\
\hline $\begin{array}{l}\text { Merriman Cement } \\
\text { Products, Inc. }\end{array}$ & Cement blocks & Less than 10 & 2 miles \\
\hline $\begin{array}{l}\text { Stiles Gauge Pin } \\
\text { Company }\end{array}$ & Gauge pins & Less than 10 & 9 miles \\
\hline $\begin{array}{l}\text { West Jefferson Sand } \\
\text { and Gravel Company }\end{array}$ & Sand and gravel & Less than 10 & 3 miles \\
\hline
\end{tabular}

(a) May, 1956.

(b) Seasonal. In full operating in August and September, only. Closed in 1954. 


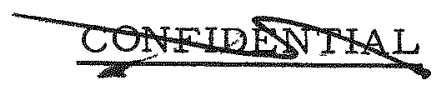

45

The primary prevailing wind direction is from the southerly quadrant (41 per cent of the winds blow from the general direction SE to SW). The secondary prevailing direction is from the NW. The average wind speed is $8.4 \mathrm{mph}$ with 58 per cent of the winds occurring in the 4 to 12 -mph interval. No large seasonal or diurnal variation exists in either the direction or speed of the winds. During a 51-year period in Columbus, peak wind speeds have been observed to exceed $51 \mathrm{mph}$ in every month of the year. The maximum recorded speed was $84 \mathrm{mph}$ occurring in July.

Rainfall, averaging nearly $3-1 / 2$ in. per month, is quite evenly distributed from April to August. The record single day's rain was 3.87 in. in July, 1947. The bulk of the summer rainfall comes in frequent thunderstorms, and tornadoes are not unknown. However, local storm records show that only 4 tornadoes occurred in the Columbus area since 1931.

Since Ohio is located in the path of many winter storms, Columbus receives a generous amount of cold-season precipitation. The bulk of it comes in the form of rain, but the average winter will yield a total of $22 \mathrm{in}$. of snow. This is quite variable and, in the largest snowfall of recent times, in $1950,7.5 \mathrm{in.}$ fell in one day.

Climatology data abstracted from a report prepared by the Scientific Division of the U. S. Weather Bureau is given in Appendix B.

Geology and Hydrology

The principal glacial deposits at the surface in the Battelle site area consist of till and outwash which accumulated as the Wisconsin ice sheet of the Pleistocene Age receded. The till, an unstratified matrix of clay containing rock fragments, underlies the Battelle site to depths ranging from approximately 60 to $200 \mathrm{ft}$. The outwash, composed of stratified layers of sand and gravel, is thin and discontinuous in the site vicinity. Fringing the locality is a narrow strip of Columbus limestone, forming in places a $3-f t$ surface stratum.

Underlying the glacial deposits of the area are several hundred feet of nearly horizontal beds of limestone, dolomite, and shale through which preglacial streams carved a branched valley system. The distance from the soil surface to the bedrock on the Battelle property ranges from a few feet in areas along Big Darby Creek to over $200 \mathrm{ft}$ in the northwest corner of the property.

There are two aquifers in the Battelle site area. One is shallow and of minor importance and is underlain by the major aquifer of sand, gravel, and limestone. Yields up to 300 gallons per minute have been obtained from wells drilled into the principal aquifer in the area.

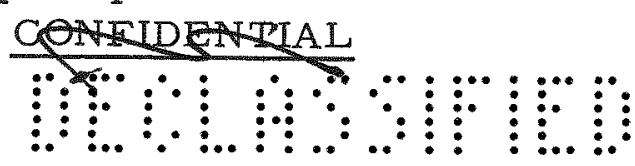




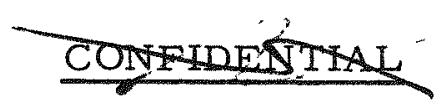

46

The ground water comes entirely from local precipitation and the shallow aquifer is recharged almost uniformly from the precipitation. The water table is everywhere less than $40 \mathrm{ft}$ from the surface, and the contours are a subdued replica of the surface topography. Calculations indicate that water in the principal aquifer in the vicinity of the Battelle site is moving at a rate somewhat less than $1 \mathrm{ft}$ per day. The water in the till overlying the principal aquifer is estimated to flow at a considerably lower rate, measur able in hundredths of a foot per day.

Ground-water movement downward through the thick till takes place very slowly. A long period of slow percolation occurs before water reaches a zone in which it may move laterally at appreciable rates. All the ground water is discharged into Big Darby Creek; hence, water entering the ground on the Battelle property is already near its place of discharge.

Big Darby Creek accounts for the principal surface-water flow. The mean flow is $420 \mathrm{ft}^{3}$ per sec, based on a 24 -year record. Ground-water seepage from the impermeable deposits in Madison County adds little to stream flow. The water of Big Darby Creek is of good quality and is not polluted.

The conclusions of a report prepared by the U. S. Geological Survey on the geology and hydrology of the Battelle site are given in Appendix C. It is concluded that in case of liquid spillage most of the liquid would flow overland to the Big Darby Creek and the remainder, once reaching the water table, would also discharge into the creek. The chances for radioactive contamination of well water in the surrounding area are considered nil.

\section{NORMAL OPERATING HAZARDS}

Certain hazards can be associated with the critical assembly during normal operation. These hazards cannot be guarded against by automatic devices, and, consequently, proper design and administration must be used. A number of these hazards, with the precautions taken to minimize the associated danger, are listed below.

Radiation Level in the Building

Calculations were made to estimate the radiation in the control room during normal operation. These estimates indicate a gamma dose rate of about $0.16 \mathrm{mr} /(\mathrm{hr})(\mathrm{w})$. The calculations were based on experimental data from the Bulk Shielding Facility. The fast and thermal fluxes are estimated to be $<1$ and 100 neutrons $/\left(\mathrm{cm}^{2}\right)(\mathrm{sec})(\mathrm{w})$, respectively. The maximum

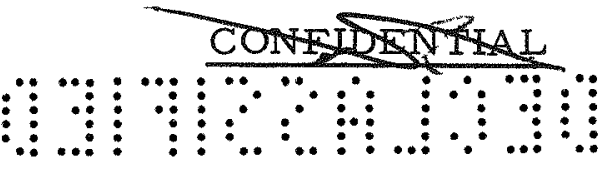




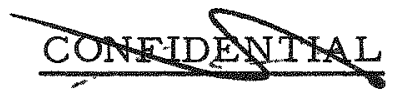

47

permissible external radiation doses are assumed(2) to be 66 neutrons/ $\left(\mathrm{cm}^{2}\right)(\mathrm{sec})$ for fast neutrons, 1750 neutrons $/\left(\mathrm{cm}^{2}\right)(\mathrm{sec})$ for slow neutrons, and $300 \mathrm{mr}$ per week for gamma rays. The radiation level in the control room for the estimated normal operating power of $1 \mathrm{w}$ is much less than the se tolerance doses.

The only parts of the building with a radiation level greater than the control room will be the reactor room and, possibly, the vault and fuelelement-assembly area. These areas will not be occupied when the reactor is in operation. The radiation in the rest of the building will be checked during reactor operation and corrective measures will be taken in the event of excessive radiation levels.

\section{Escape of Fission Products}

The uranium strips to be used in this experiment will be coated with $0.0002 \pm 0.0001 \mathrm{in}$. of Teflon. This coating should prevent the escape of all but about $1 / 2$ per cent of the fission products. Components of the lattice will be checked by swipe counts to determine the extent of external contamination. All components will be handled with gloves.

\section{HAZARDS AFTER AN ACCIDENT}

Of major concern here are the hazards created in the area following a reactor accident. In most azimuthal directions, the exclusion radius is considerably more than $1500 \mathrm{ft}$. The minimum distance to the fence is 1200 ft and a swamp is on the other side of this fence. Thus, an actual vaporization and release of the fuel elements must occur to endanger public persons. Possible danger to the population might result from (1) direct irradiation by a cloud of fission product gases, (2) direct irradiation by contaminated ground surfaces due to a fall-out or rain-out from the cloud, and (3) inhalation of radioactive particles or gases and other toxic materials.

\section{Radiation From Radioactive Cloud}

To evaluate the cloud problem, the nomographs constructed by J. Z. Holland were employed. The meteorological data were prepared by the Scientific Services Division of the U. S. Weather Bureau and are shown in Table 3. 


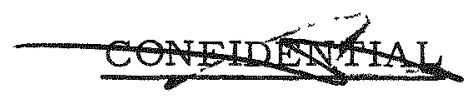

48

TABLE 3. PARAMETERS FOR DOSAGE CALCULATIONS(a)

\begin{tabular}{rllll}
\hline & & & \multicolumn{1}{c}{$\mathrm{c}^{2}$} \\
\cline { 3 - 5 } $\mathrm{h}$ & $\mathrm{n}$ & $\mathrm{u}-1$ & $\mathrm{u}-5$ & $\mathrm{u}-10$ \\
\hline \multirow{2}{*}{25} & $1 / 5$ & .064 & .046 & .040 \\
& $1 / 4$ & .021 & .014 & .012 \\
& $1 / 3$ & .009 & .005 & .004 \\
& $1 / 2$ & .006 & .002 & .002 \\
50 & $1 / 4$ & .015 & .010 & .008 \\
100 & $1 / 4$ & .008 & .005 & .004 \\
\hline
\end{tabular}

(a) $\mathrm{h}=$ height of cloud from ground, $m$

$\mathrm{u}=$ mean wind speed, $\mathrm{m} / \mathrm{sec} \quad \underline{\mathrm{n}}$

$c=$ virtual diffusion coefficient, $\mathrm{m}^{2}$

$\mathrm{n}=$ Sutton stability index, dimensionless.

The stability parameter, $n$, may vary from 0 to 1 such as

$\begin{array}{lc}\text { Large lapse } & 1 / 5 \\ \text { Zero or small lapse } & 1 / 4 \\ \text { Modified inversion } & 1 / 3 \\ \text { Large inversion } & 1 / 2\end{array}$

Using the se data and the nomographs, the total radiation dose was determined for various distances downwind from the reactor for a megawatt-second fission-energy release. It was estimated that the initial cloud height and cloud radius would be $25 \mathrm{~m}$ and $8 \mathrm{~m}$, respectively. The results are shown graphically in Figure 14 for several meteorological conditions.

From Figure 14 it may be noted that at the exclusion area limit the dose is approximately $0.03 \mathrm{r}$ per megawatt-sec. To attain a lethal dose at this location, i.e., one expected to kill about one-half of the persons exposed to it $(\sim 400 \mathrm{r})$, would require an accident characterized by a $1.3 \mathrm{x}$ $10^{4}$ megawatt-sec fission-energy release. It is shown in a later part of the report that even for a very severe accident the fission energy release does not approach this value. 


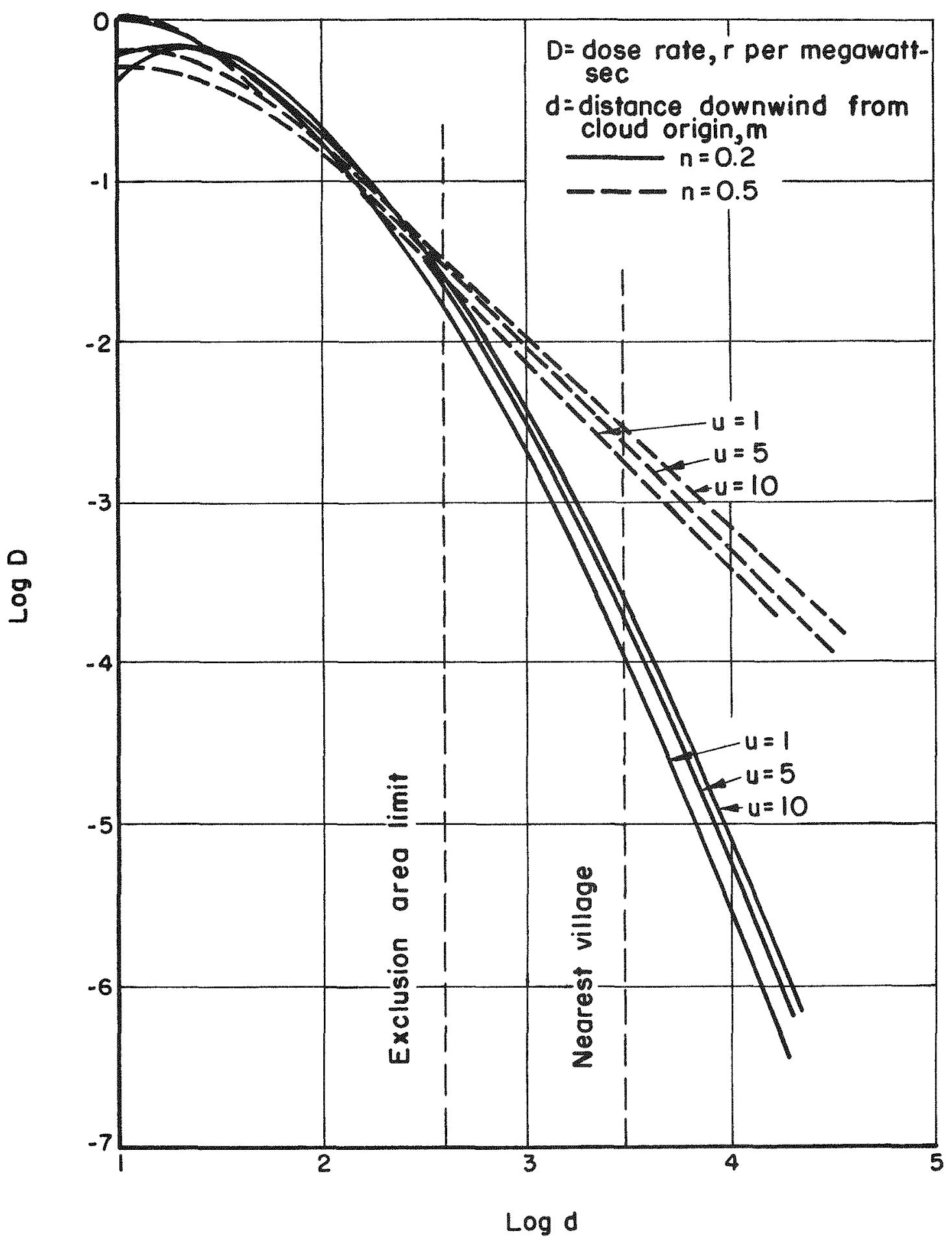

( $d=$ Distance Downwind From Cloud Origin) $\quad$ - 18546

FIGURE 14. DOSES DUE TO PASSING RADIOACTIVE CLOUD

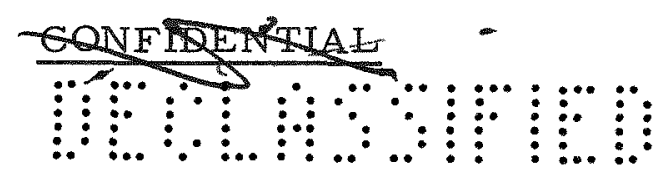




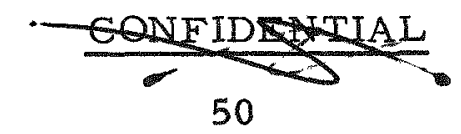

Radiation Due to Fall-Out or Rain-Out

From the Radioactive Cloud

In this case, the fission products contained in the cloud following an accident are assumed to fall to the ground as the cloud travels downwind. The dose $1 \mathrm{~m}$ above ground level after the fall-out was calculated as a function of distance downwind. The equations used are reported in Appendix D. The doses calculated are shown in Figure 15.

From Figure 15 it may be noted that at the exclusion-area limit the integrated dose is approximately $2.5 \mathrm{r}$ per megawatt-sec and at the nearest village the dose is approximately $0.1 \mathrm{r}$ per megawatt-sec. It should be emphasized that these doses are based upon continuous long-term exposure following fall-out. If a shorter, more practical, length of exposure is considered, the dose is much less. For instance, in the first hour of exposure at the nearest village, the dose is only $0.028 \mathrm{r}$ per megawatt-sec.

\section{Inhalation of Radioactive Material}

The equations used for calculating the inhalation activity are given in Appendix D. The results are shown graphically in Figures 16 and 17.

The maximum permissible amounts of the various isotopes of major concern are given in Table 4.

\section{TABLE 4. MAXIMUM PERMISSIBLE AMOUNTS OF SOME ISOTOPES}

\begin{tabular}{lc}
\hline \multicolumn{1}{c}{ Isotope } & $\begin{array}{c}\text { Maximum Permissible Amounts } \\
\text { in Total Body, } \mu \text { curies }\end{array}$ \\
\hline $\mathrm{I}^{131}$ & 0.3 \\
$\mathrm{Sr}^{89}$ & 2.0 \\
$\mathrm{Sr}^{90}+\mathrm{Y}^{90}$ & 1.0 \\
$\mathrm{Ba}^{140}+\mathrm{La}^{140}$ & 5.0 \\
$\mathrm{Ce}^{144}+\mathrm{Pr}^{144}$ & 5.0 \\
$\mathrm{Y}^{91}$ & 15.0 \\
\hline
\end{tabular}

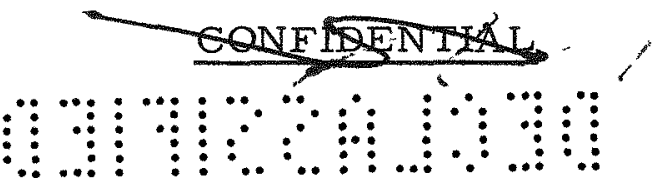




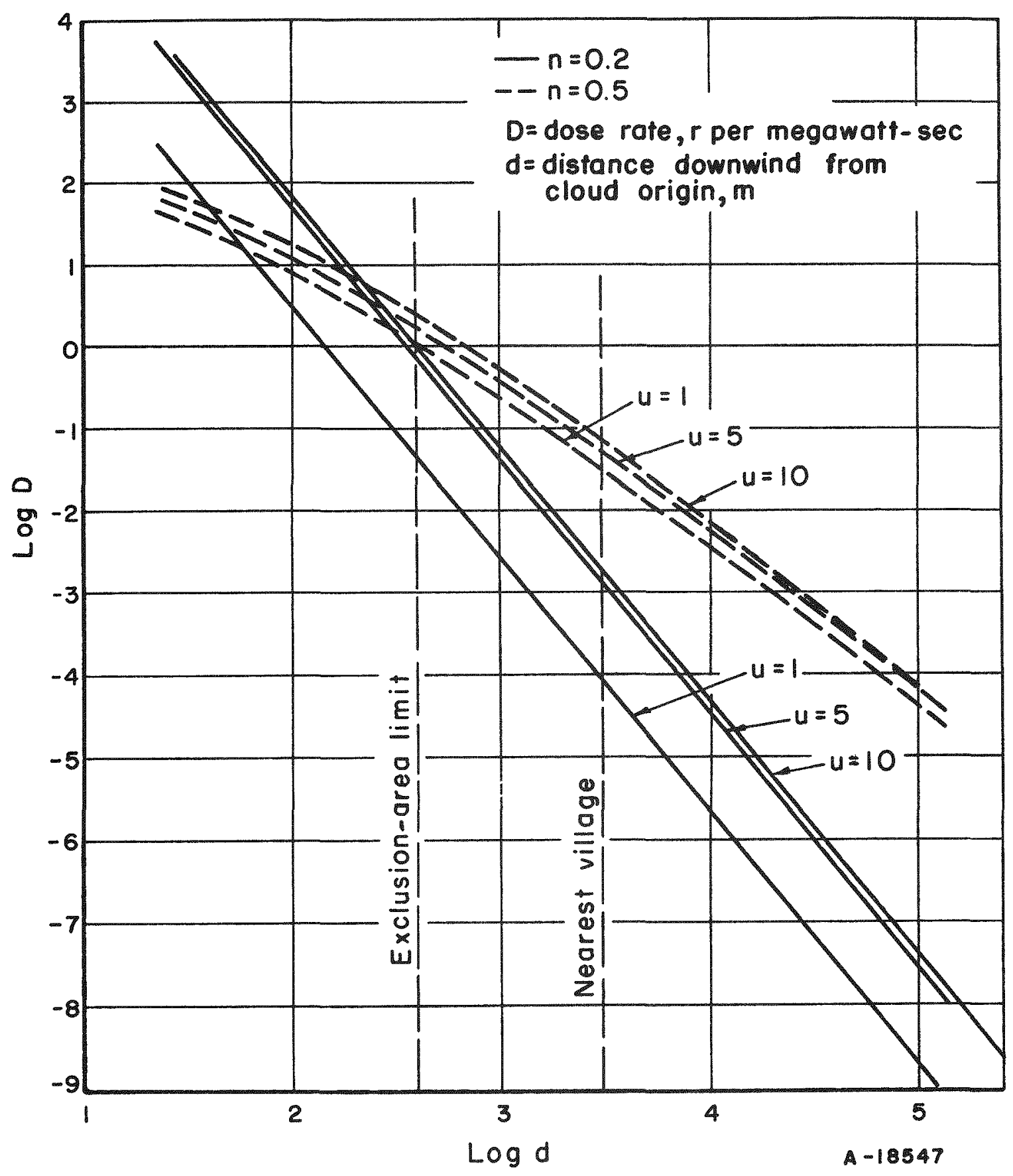

FIGURE 15. DOSES DUE TO FALL-OUT FROM PASSING RADIOACTIVE CLOUD

CONEIDENILA

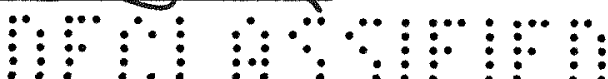




\section{CONTIDETIAX}

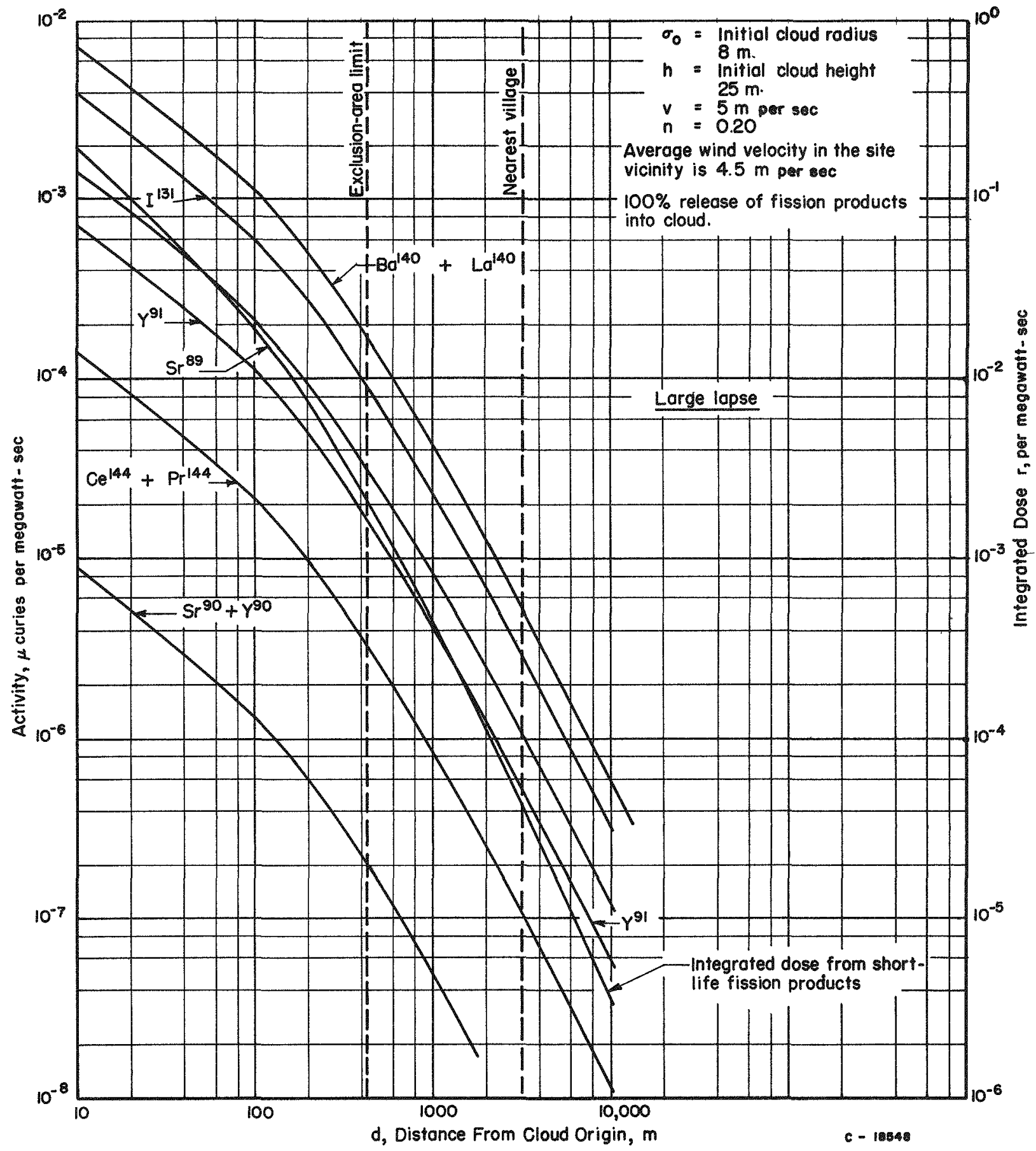

FIGURE 16. INHALATION ACTIVITIES FROM RADIOACTIVE CLOUD (LARGE LAPSE)
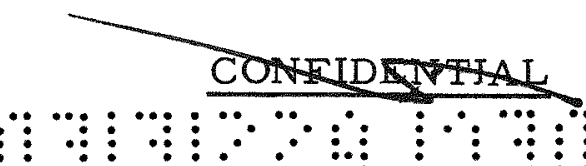

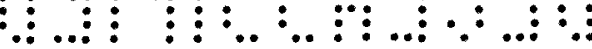




\section{CONFADESNINAL}

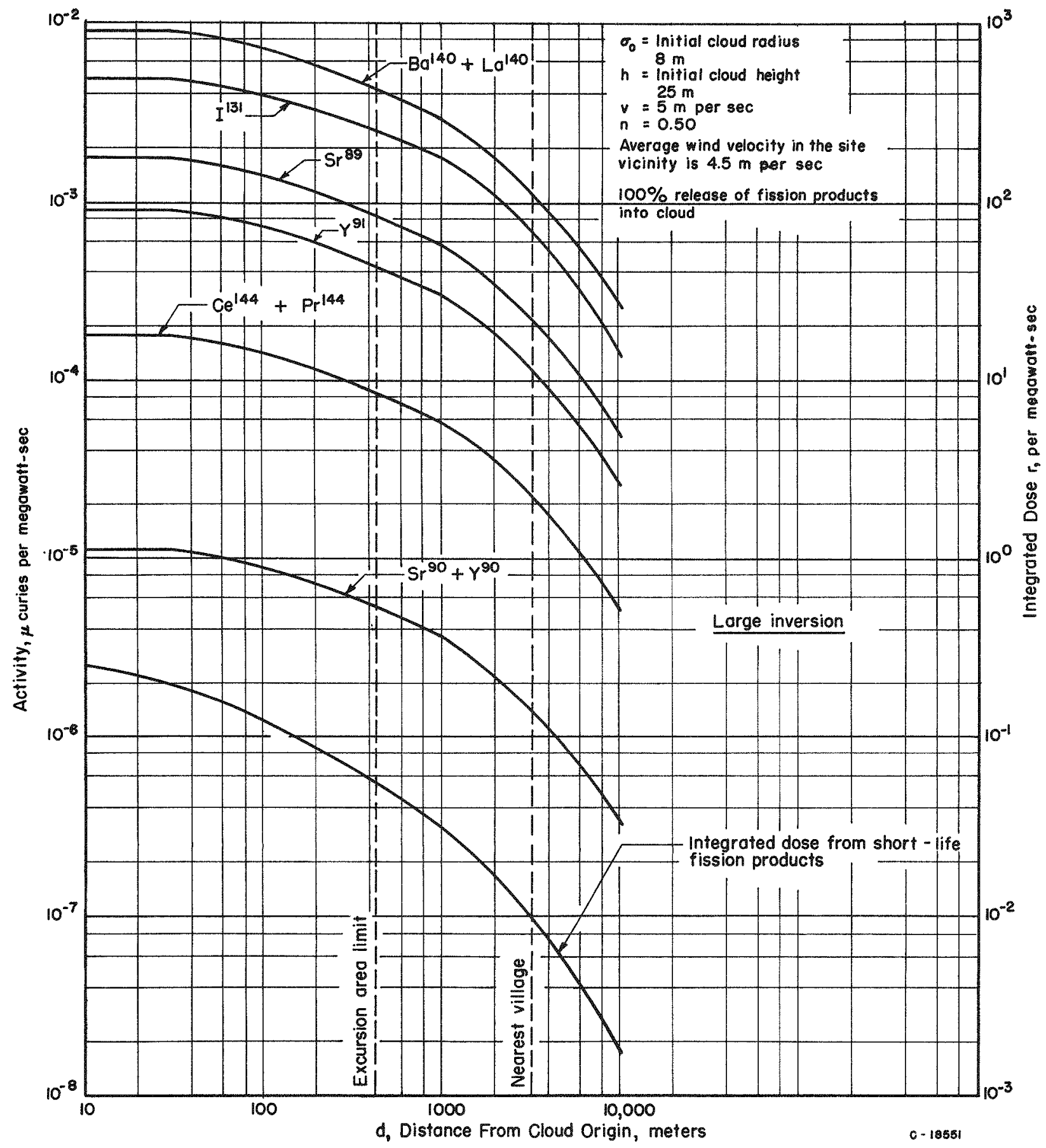

FIGURE 17. INHALATION ACTIVITIES FROM RADIOACTIVE CLOUD (LARGE INVERSION)

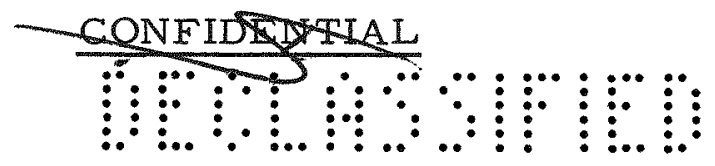




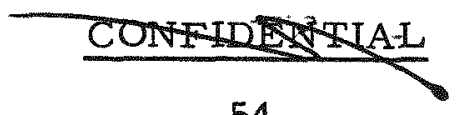

54

The most critical isotope is iodine-131. From Figure 17 the activity of this isotope for the worst diffusion conditions is $2.5 \times 10^{-3} \mu$ curies per megawatt-sec at the exclusion-area limit and $7 \times 10^{-4} \mu$ curies per megawatt-sec at the nearest village. Thus an accident of greater than 100 megawatt-sec is necessary to exceed the permissible tolerance value at the exclusion-area limit and an accident greater than 4000 megawatt-sec is necessary to exceed the permissible tolerance value at the nearest village.

\section{POSSIBLE ACCIDENTS}

The accidents to be considered here are those which would result in a possible widespread release of radioactivity. This must necessarily include a reactor transient because the equilibrium quantity of fission products present during normal operation is low enough so that no serious off-site hazard would result if these were released by some mechanism.

\section{Possible Reactivity Additions}

Several possible methods by which excess reactivity could be accidentally introduced into the critical assembly are listed below. These accidents require a combination of human errors and mechanical failures and would, therefore, appear to have a low probability of happening.

(1) Continued withdrawal of all safety and control rods even though the reactor becomes critical during this withdrawal. Based on the control-plate calibrations, and the rod withdrawal rate of 22 in. per min, the maximum rate of $\Delta \mathrm{k} / \mathrm{k}$ addition possible this way is about $0.01 \Delta \mathrm{k} / \mathrm{k}$ per sec.

(2) Table closing at maximum rate (25 in. per min) with the reactor becoming critical at some separation distance, combined with a failure of the safety rods to operate. Under this condition the maximum rate of $\Delta \mathrm{k} / \mathrm{k}$ addition is about 0.021 $\Delta \mathrm{k} / \mathrm{k}$ per sec (see Figure 13).

(3) The sudden introduction of reflector material in the 6-in. lateral gap when the reactor is critical. This might happen if the normal procedures and devices for preventing the reflector polyethylene from falling into the gap were not employed. For the case where the gap extended the full length of the core, this case would approximate a step function addition of $0.10 \Delta \mathrm{k} / \mathrm{k}$.

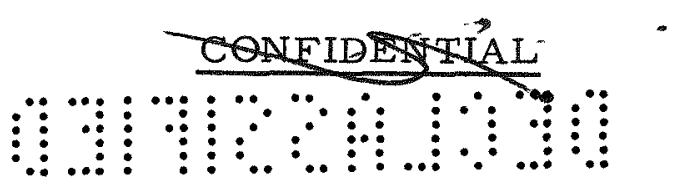




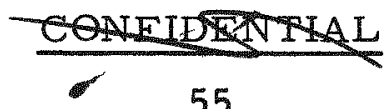

55

\section{Energy Releases}

The radioactivity released in a nuclear accident was estimated as indicated in Appendix $D$. The nuclear energy released is plotted against the instantaneous $\Delta \mathrm{k} / \mathrm{k}$ added in Figure 18. The shutdown mechanism was assumed to be disassembly of the core for these calculations. It may be assumed that all the fission products are released for, although the nuclear energy alone is not sufficient to vaporize all the fuel, it seems reasonable to assume that energy from chemical reactions such as oxidation of the uranium will be sufficient to cause complete vaporization in the event of a serious accident.

The worst of the postulated accidents is an instantaneous addition of $0.1 \Delta \mathrm{k} / \mathrm{k}$. This may be seen to give a nuclear-energy release of 25 megawatt-sec.

For the case of a continuous addition of $0.021 \Delta \mathrm{k} / \mathrm{k}$ per sec due to closing of the table, it is shown in Appendix $D$ that this corresponds to an instantaneous $\Delta \mathrm{k} / \mathrm{k}$ addition of 0.0061 , which corresponds to a fissionenergy release of 8 megawatt-sec.

\section{DISCUSSION}

The results of the hazards calculations show that the exclusion area is adequate to reduce the dose to a reasonable value even for the maximum hypothetical accident. For the maximum estimated fission-energy release of 25 megawatt-sec, the cloud dose at the exclusion-area limit is only about $0.8 \mathrm{r}$, and $0.08 \mathrm{r}$ at the nearest village. The fall-out calculations give integrated doses over infinite time to be about $62 \mathrm{r}$ at the exclusion-area limit and 2. $5 r$ at the nearest village. Inhalation doses are even less serious than the other hazards considered.

The most severe case imagined here would appear to give an off-site dose much less than that expected to be lethal to one-half the persons exposed $(\sim 400 \mathrm{r})$.

\section{CONFIDENTAL}



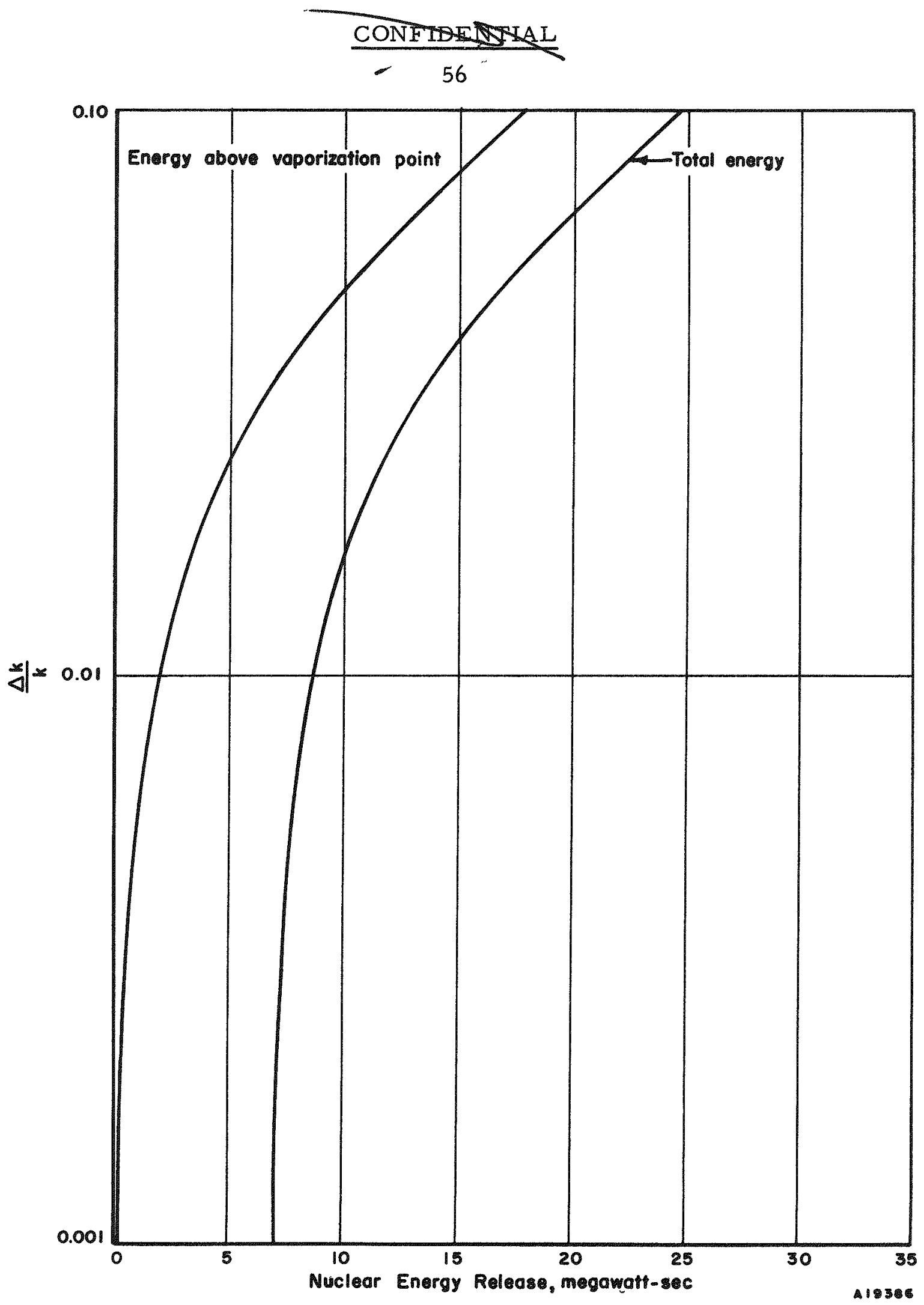

FIGURE 18. NUCLEAR-ENERGY RELEASE

GQNFIDSNIAL

״: 


\section{REFERENCES}

(1) Handbook of Plastics, D. Van Nostrand.

(2) Hogerton, J. F., and Grass, R. C., The Reactor Handbook, Vol 1, Physics, AECD-3645.

(3) Personal Communication, R. F. Redmond.

FJJ:WSH:RFR:JWC:SLF/nlh

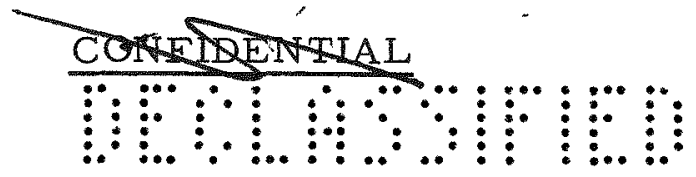


$-,-$.

•

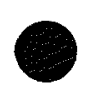

ตालमाँ 


\section{CONFID ENTALI}

59

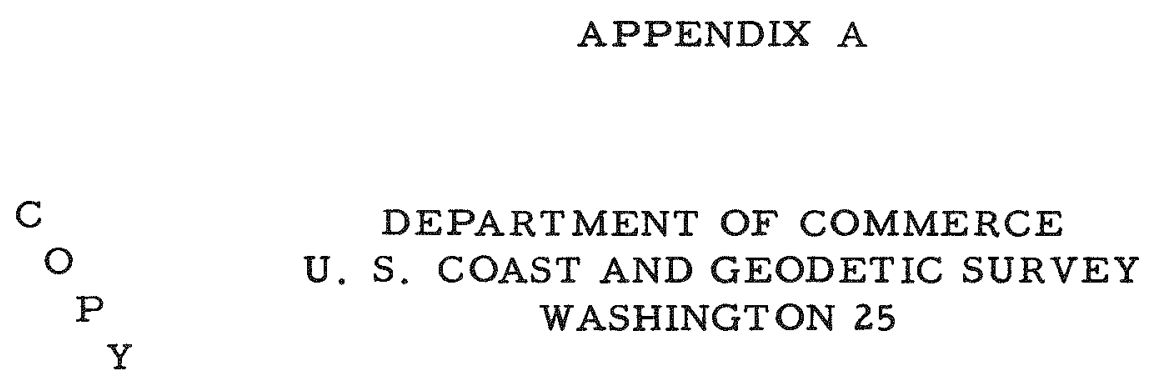

August 24, 1954

Mr. James N. Anno, Jr.

Battelle Memorial Institute

505 King Avenue

Columbus 1, Ohio

Dear Sir:

Replying to your request of August 19, 1954, we find no record of earthquakes having occurred in West Jefferson, Ohio, and immediate vicinity. However, as Rev. V. C. Stechschulte stated, there have been several minor earthquakes in western Ohio. Among the most noteworthy are the following which are briefly described in SP 609, Part 1, Earthquake History of the United States.

1776 Muskingum River, Ohio
1875 Urbana \& Sidney
1884 Columbus
1901 Wellston \& Portsmouth
1909 Ohio Valley (38.7 N. \& 86.5 W.)
1929 Bellefontaine
1931 Anna
1937 Anna \& Sidney (Mar. 2 and 7)

If we may be of further service please do not hesitate to write again.

Very truly yours,

/s/ Robert W. Knox

Acting Director

Enclosure

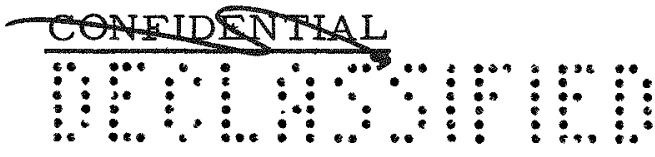




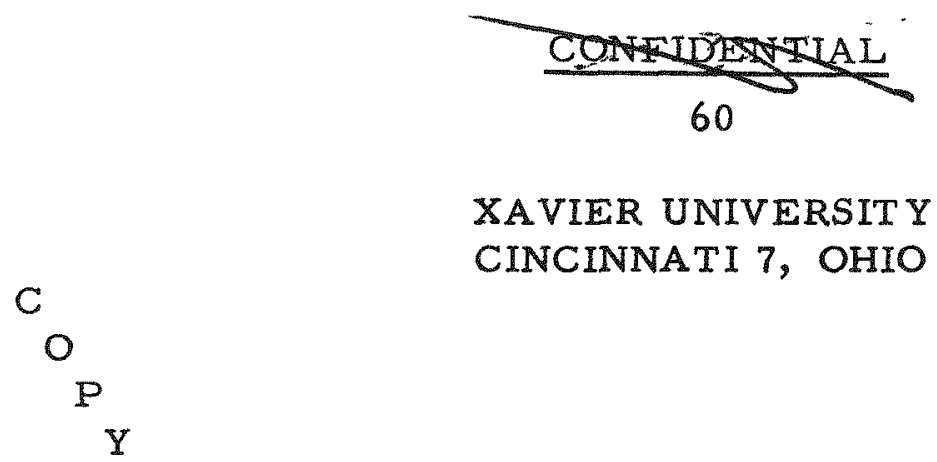

August 18, 1954

Mr. Jim Anno

Battelle Memorial Institute

Columbus, Ohio

Dear Mr. Anno:

This is in reply to your telephoned request of yesterday afternoon.

The problem of determining seismic risk in a given area is largely a guessing game. All that can be done is to list the earthquakes, with the damage done, that have occurred there within the comparatively few years of our historical record, and then to say that where earthquakes have occurred in the past, they may more likely occur again in the future rather than in places where there has been no seismic record.

The catalogs that would be pertinent to your purpose would be:

Serial 609, Earthquake History of the U. S., Part I (pp 39-46).

Serial No. 511, United States Earthquakes, 1929 (p. 8)

Serial No. 553, " " " $" 1931(p .7)$

Serial No. 619, " " " $" 1937(p .8,9)$.

These will give you more detail than is indicated by the maps, listing places where the earthquakes were felt and where damage may have been reported. What it will all add up to is that there has been minor damage approximately within the 50-mile circle with more severe damage in a small area around Anna, Ohio. The small earthquake in the vicinity of Zanesville two or three years ago would make no significant change in the picture.

Sincerely yours,

V. C. Stechschulte, S. J.

(Rev.) V. C. Stechschulte, S. J.

Director of the Seismological

Observatory 


\section{CONFHDENTHL}

61

\section{APPENDIX B}

\section{METEOROLOGY REPORT}

Introduction

The purpose of this report is to review the meteorology of the Columbus, Ohio, area for use in the site evaluation and compilation of a hazards analysis.

\section{Source of Data}

Although no meteorological data exist for the proposed site itself, very complete meteorological records have been taken for many years at several locations in Columbus. There does not appear to be any significant difference in the general topography of the area between the site and Columbus, so, for most purposes, the meteorological data which have been previously collected should be adequate for this preliminary evaluation. The Local Climatological Data* for Columbus, Ohio, presents a good general description of the weather of this area. The table headed Normals, Means and Extremes on page 2 of this annual summary presents average data on temperature, degree days, precipitation, snow, humidity, wind, etc.

\section{Climatological Review}

In the present brief report, those meteorological parameters will be stressed which influence directly the spread of atmospheric wastes.

\section{Surface Wind Direction}

The hourly wind observations for a 6-year period, 1948-1953, for the Weather Bureau Airport Station (WBAS) at Columbus were studied in detail. Table B-l presents the percentage frequency of the wind direction. The prevailing wind direction is from the southerly quadrant ( 41 per cent of winds blow from the general direction SE through SW). The secondary prevailing direction is from the NW. There does not appear to be any major change in

U. S. Department of Commerce, Weather Bureau, "Local Climatological Data", for 1953, Columbus, Ohio, U.S. Government Printing Office, price 10 cents,

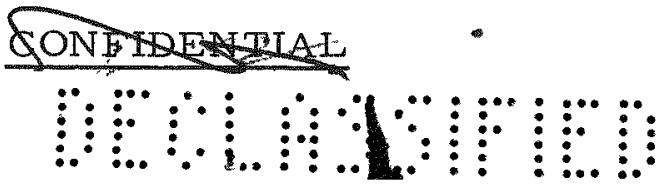


TABLE B-1. PERCENTAGE FREQUENCY OF WIND DIRECTION, WEA THER BUREAU AIRPORT STATION, COLUMBUS, OHIO

(Based on hourly observations January, 1943, through December, 1953)

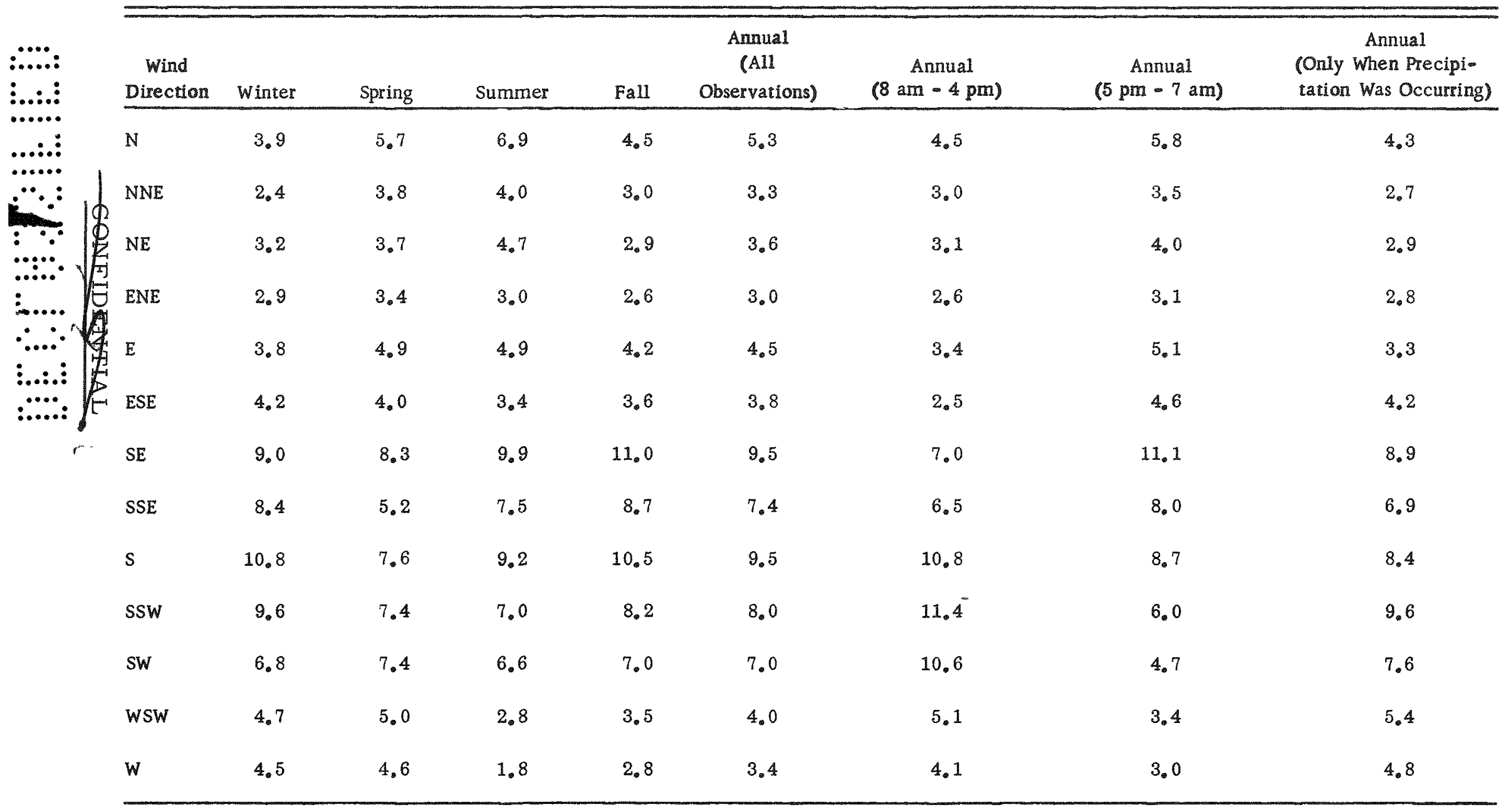


TABLE B 1 . (Continued)

\begin{tabular}{|c|c|c|c|c|c|c|c|c|}
\hline $\begin{array}{c}\text { Wind } \\
\text { Direction }\end{array}$ & Winter & Spring & Summer & Fall & $\begin{array}{c}\text { Annual } \\
\text { (All } \\
\text { Observations) }\end{array}$ & $\begin{array}{c}\text { Annual } \\
(8 \mathrm{am}-4 \mathrm{pm})\end{array}$ & $\begin{array}{c}\text { Annual } \\
(5 \mathrm{pm}-7 \mathrm{am})\end{array}$ & $\begin{array}{l}\text { Annual } \\
\text { Conly When Precipi } \\
\text { tation Was Occuring }\end{array}$ \\
\hline WNW & 7.5 & 7.1 & 3.8 & 5.2 & 5.9 & 6.7 & 5.5 & 8.6 \\
\hline NW & 9.8 & 10.9 & 8.3 & 9.1 & 9.6 & 9.8 & 9.4 & 11.2 \\
\hline NNW & 6.1 & 7.6 & 8.0 & 7.4 & 7.3 & 7.4 & 7.3 & 6.8 \\
\hline Calm & 2.4 & 3.4 & 8.1 & 5.7 & 4.9 & 1.6 & 6.9 & 1.3 \\
\hline
\end{tabular}

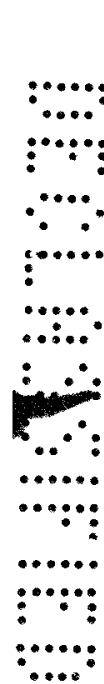


wind-direction frequency from season to season except that northwesterly winds predominate in the Spring, while the south and southeast winds reach their maximum frequency in the fall. Table B-1 also compares the wind frequencies for two periods of the day $-8 \mathrm{am}$ to $4 \mathrm{pm}$ and $5 \mathrm{pm}$ to $7 \mathrm{am}$. From a study of these data, it is clear that no large diurnal change in the wind direction should be expected on the average, although night-time conditions favor southeasterly directions and calms, whereas the prevailing daytime wind is south-southwest.

It is necessary to examine the wind structure during periods of precipitation in order to consider the effect of wash-out of possible waste contaminants. Table $\mathrm{B}-1$ also presents the percentage frequency of wind directions at Columbus during those hours when precipitation was falling. (This was approximately 15 per cent of the time.) In this case, also, there does not appear to be any major shift in the prevailing wind direction frequencies, although $\mathrm{NW}$ is the primary maximum in this case.

Wind direction is also important when the lower atmosphere is very stable and atmospheric diffusion is at a minimum. From other meteorological studies of this correlation (Cincinnati, Dayton, and Detroit), it seems probable that the most stable weather in the Columbus area would accompany the southerly and southeasterly winds. The northwesterly winds would be associated with unstable or good diffusion atmospheric conditions. This tendency is borne out by the seasonal and diurnal variations, spring and daytime being the periods in which low-level instability is most common.

\section{Surface Wind Speed}

Table $B-2$ presents the percentage frequency of wind speeds in various class intervals. There is a striking persistency to the distribution. Approximately 58 per cent of the winds in the Columbus area will occur in the 4 to $12-\mathrm{mph}$ speed interval. The average speed is $8.4 \mathrm{mph}$, although it is slightly weaker in the summer months and stronger in the winter. Winds less than $4 \mathrm{mph}$ occur approximately 21 per cent of the time on the average (10 per cent during the day, 28 per cent during the night, and 10 per cent during those hours when precipitation is occurring). During a 51 -year period in Columbus, peak wind speeds have been observed to exceed $51 \mathrm{mph}$ during every month of the year. The highest recorded speed was $84 \mathrm{mph}$ during July.

Two very localized types of storms which are accompanied with high wind speeds deserve special mention - thunderstorms and tornadoes. Thunderstorms occur on the average of 41 days per year, primarily in the late spring and summer, although they have occurred during every month of the year. The peak activity is in June and July. These months average 8 thunderstorm days apiece. Thunderstorm activity is extremely variable,

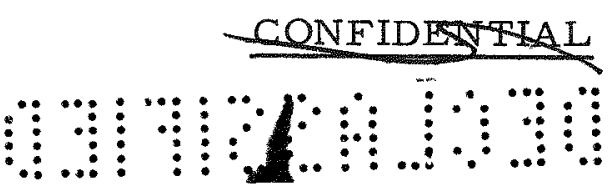


TABLE B-2, PERCENTAGE FREQUENCX OF WIND-SPEED GROUPS, WEATHER BUREAU AIRPORT STATION, COLUMBUS, OHIO

(Based on hourly observations January, 1248, through December, 1953)

\begin{tabular}{|c|c|c|c|c|c|c|c|c|}
\hline $\begin{array}{l}\text { Wind } \\
\text { Speed. } \\
\text { mph }\end{array}$ & Winter & Spring & Summer & Fall & $\begin{array}{l}\text { Annual } \\
\text { (All } \\
\text { Observations) }\end{array}$ & $\begin{array}{c}\text { Annual } \\
(8 \mathrm{am}-4 \mathrm{pm})\end{array}$ & $\begin{array}{c}\text { Annual } \\
(5 \mathrm{pm}-7 \mathrm{am})\end{array}$ & $\begin{array}{l}\text { Annual } \\
\text { (Oniy When Precipi- } \\
\text { tation Was Occurring) }\end{array}$ \\
\hline Calm & 2.4 & 3.4 & 8.1 & 5.7 & 4.9 & 1.6 & 6.9 & 1.3 \\
\hline $1-3$ & 12.0 & 11.9 & 23.4 & 17.7 & 16.2 & 8.9 & 20.6 & 8.5 \\
\hline $4-12$ & 57.9 & 56.2 & 59.0 & 57.6 & 57.6 & 57.2 & 57.9 & 55.0 \\
\hline $13=24$ & 27.0 & 27.8 & 9.8 & 18.8 & 20.8 & 31,5 & 14.3 & 34.2 \\
\hline $25-31$ & 0.7 & 1.0 & (a) & (a) & 0.5 & 0.7 & 0.4 & 0.9 \\
\hline $32-46$ & (a) & (a) & (a) & (a) & (a) & (a) & (a) & (a) \\
\hline 46 & - & - & - & (a) & (a) & $=$ & (a) & (a) \\
\hline $\begin{array}{l}\text { Mean } \\
\text { wind } \\
\text { speed }\end{array}$ & 9.7 & 9.7 & 6.4 & 7.9 & 8.4 & 10.5 & 7.1 & 10.8 \\
\hline
\end{tabular}

(a) Only a few observations. 


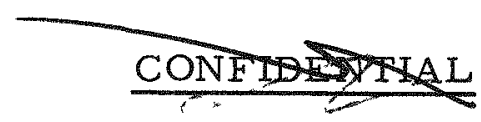

66

but a rare severe storm may cause winds in excess of $50 \mathrm{mph}, 1$ to 3 in. of rain in an hour, and hailstones $1 / 2 \mathrm{in.}$ or larger in diameter. Situations favorable for the formation of severe thunderstorms are also conducive to tornado formation. However, this more violent storm is rare in the Columbus area. A 35-year study of United States tornadoes shows that 111 tornadoes occurred in Ohio during this period, with the largest percentage of these storms in the northern and western portions of the state. Local storm records from 1931 through 1954 show only four tornadoes in the immediate Columbus area.

\section{Precipitation}

The Columbus area receives approximately 38 in. of precipitation annually, which is spread over approximately 140 days. Precipitation is distributed rather evenly throughout the year with the maximum occurring in the late spring and early summer. The maximum amount of precipitation ever observed in $24 \mathrm{hr}$ was $3.91 \mathrm{in}$. Columbus has an average snowfall of 22 in., which falls on approximately 6 days per year. The greatest amount ever recorded for a $24-\mathrm{hr}$ period was $11.9 \mathrm{in}$, and for 1 month was 29.2 in.

\section{Atmospheric Stability}

Measurements of the vertical temperature distribution are not made in the Columbus area. However, measurements made at other locations have shown a high degree of correlation between low winds periods, restricted visibility, and the occurrence of inversions. Conversely, high wind speeds and good visibility are indicative of lapse conditions and good diffusion weather. The Columbus area experiences approximately 15 days on which a heavy fog occurs for a few hours. Visibility is reduced to below 6 miles approximately 43 per cent of the hours annually. For just fog, it is reduced to below 6 miles approximately 8 per cent of the time.

Inversions form nearly every night, but there is nothing in the records which could be interpreted to signify that the Columbus area experiences an unusual amount of poor atmospheric stability conditions. 


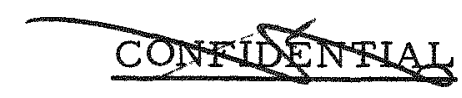

67

APPENDIX C

\section{CONCLUSIONS OF GEOLOGY AND HYDROLOGY REPORT}

The conclusions of a report* on the geology and hydrology of the Battelle site are reprinted here. This report appears in full in a previous hazards report on the critical assembly. **

"The Battelle site seems to be almost entirely safe for the operation of a nuclear power reactor, with respect to the effects on the ground water resources resulting from accidental spillage of radioactive fluids in the site area. In the event of a spill, most of the liquid would flow overland to Darby Creek. Only a small portion would infiltrate the soil and seep downward to the water table or reach the principal artesian aquifer.

"Infiltration would be greatest when the soil is dry, especially during periods of large soil moisture deficiency, such as would occur during the growing season. Conditions least favorable for infiltration, and those which would promote most rapid runoff, would result from frozen or saturated ground, or would occur during a heavy rainstorm when a large volume of water is flowing overland towards Darby Creek.

"The course of a spilled liquid, once it reached the water table, also would be towards Darby Creek where it would discharge into the stream through springs and seeps. The shallow aquifer is unimportant as a source of water in the site area and the chances are almost nil under present conditions that a contaminant introduced into the shallow aquifer on the Battelle property would be diverted to wells or otherwise intercepted by man in the course of its slow underground journey to the discharge area.

"A greater chance for contamination of ground water supplies would result from radioactive fluid entering the principal aquifer in the site area. This danger is slight, however, for the principal aquifer receives most of its recharge in upland areas some distance west of the Battelle site. Only a relatively small amount of water percolates through the till to reach the principal aquifer in the immediate area of the site. Moreover, a contaminant reaching the principal aquifer in the immediate area of the Battelle property would already be down-gradient from almost all the wells in the area.

\footnotetext{
- Norris, Stanley, "Hydrology of a Proposed Reactor Sire Near Columbus, Ohio", U. S. Geological Survey, Water Resources Division, Columbus, Ohio (August, 1954).

- BMI-ACRS -600 .
}

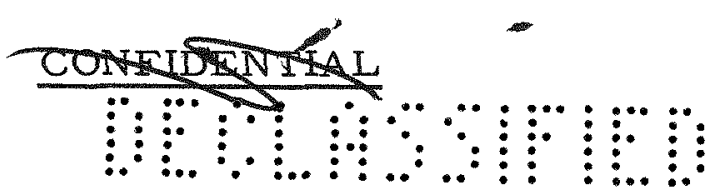


"Practically the only potential danger of contamination to a specific ground water supply is to the supply now being developed by the Battelle Memorial Institute near the southeast corner of their property. Pumping from the well now being drilled, and from possible future wells, would lower ground water levels in the principal aquifer in the immediate area of the wells. This would induce more recharge locally from the overlying till by creating a cone of influence which might encompass areas where the danger of contamination would be greatest. In view of this possibility a careful record should be maintained of the natural radioactivity of the water from the Battelle plant wells, to be used as a basis for comparison to detect any contamination should spillage occur.

"The greatest danger to human life and property resulting from spillage of radioactive fluid in the Battelle site area would be for the fluid to reach Darby Creek in volume and to move downstream in toxic concentration. Darby $\mathrm{Creek}$ is not now used either as a source of public or of large-scale industrial water supply, though it undoubtedly will be used eventually for both purposes. It is however, an important source of water for stock all along its course and it flows into the Scioto River above several important water supply developments, including the supply for the Atomic Energy Commission plant in Pike County.

"The velocity of flow in Darby Creek ranges from very low, when the stream is in pool stage and the only perceptible flow is over the riffles, to very high when the stream is in flood. The velocity of flow is important to any further evaluation of the fate of a spilled liquid once it reaches the stream and it should be studied under various conditions of discharge. Surface water samples should be collected and analyzed to determine the natural radioactivity of the stream, and the records maintained as a basis for future comparison." 


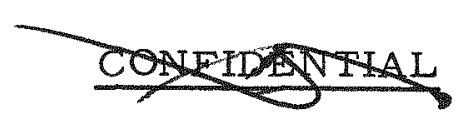

69

APPENDIX D

\section{HAZARDS CALCULATIONS}

\section{Dose Rates From Fall-Out From an Explosion Cloud}

The term wash-out is here used to describe that condition in which continuous rain-out and fall-out from a radioactive cloud occurs as it drifts downwind from the origin. The fundamental assumption is that a constant fraction of the radioactivity in the cloud falls out per unit distance as the cloud travels downwind and that for each distance this fall-out rate is that which renders the dose a maximum at that point. Assuming uniform concentration of activity and correcting for attenuation, the dose rate may be expressed as*

$$
D_{r}=\frac{2 \sqrt{\pi} a C_{x}}{\sigma} E_{1}\left(\frac{h}{\lambda}\right),
$$

where

$$
\begin{aligned}
& D_{r}=\text { dose rate, } r /(h r)(\text { megawatt-sec) } \\
& \alpha=\text { unit dose rate per unit concentration on the } \\
& \text { ground, } 0.57 \mathrm{E} \text { (mev), } \frac{\mathrm{r}-\mathrm{m}^{2}}{\text { curie }-\mathrm{hr}} \\
& E=\text { energy per disintegration, } 0.5 \mathrm{mev} \\
& C_{\mathrm{x}}=\frac{\mathrm{C}_{\mathrm{o}}}{\mathrm{eX}_{\mathrm{o}}} \\
& \mathrm{X}_{0}=\text { distance from cloud origin to the point where } \\
& \text { the dose rate is being considered, } m \\
& \mathrm{C}_{\mathrm{O}}=\text { activity of the cloud without fall-out but including } \\
& \text { decay at distance } X_{O} \text {, curies per megawat-sec } \\
& \sigma=\text { cloud radius at distance } \mathrm{X}_{\mathrm{o}}, \mathrm{m} \\
& =E_{1}\left(\frac{h}{\lambda}\right)=\int_{\left(\frac{h}{\lambda}\right)}^{\infty} \frac{e^{-t}}{t} d t
\end{aligned}
$$

Fitzgerald, J. J., Hurwitz, $\mathrm{H}_{\text {, }}$ Ir., and Tonks, L., "Method of Evaluating Radiation Hazards From a Nuclear Incident", KAPL 1045 (1954).

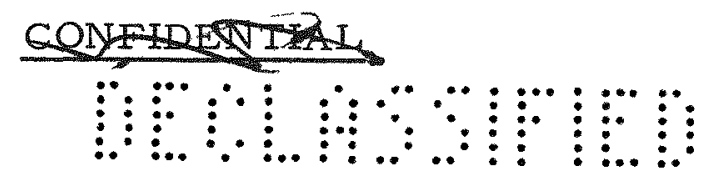




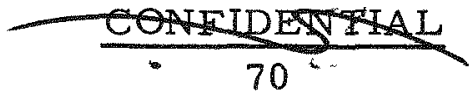

$h=$ height above the ground that the dose is measured

$(1 \mathrm{~m})$

$\lambda=$ attenuation length, $200 \mathrm{~m}$.

The above equation overestimates the dose rate at all distances.

The value of the activity of the cloud at any time, assuming no fallout, may be derived as follows: According to the empirical relationship of Way and Wigner* the rate of release of both beta and gamma energy after fission is $\cong 2.66 t^{-1} .2 \mathrm{mev}$ per sec-fission for time between $10 \mathrm{sec}$ and 100 days after shutdown. Hence, the rate of energy release in the cloud per megawatt-sec is

$$
\frac{2.66 \times \mathrm{t}^{-1.2} \times 3 \times 10^{16} \mathrm{mev} / \mathrm{sec}}{\text { megawatt-sec }}
$$

or

$$
7.98 \times 10^{16} \mathrm{t}^{-1.2} \frac{\mathrm{mev} / \mathrm{sec}}{\mathrm{megawatt}-\mathrm{sec}} \text {, }
$$

where

$$
1 \text { megawatt-sec }=3 \times 10^{16} \text { fissions. }
$$

Hence,

$$
\begin{aligned}
C_{0} & =\frac{7.98 \times 10^{16} t^{-1.2}}{0.5 \times 3.7 \times 10^{10}} \frac{\text { curies }}{\text { megawatt-sec }} \\
& =4.31 \times 10^{6} \times t^{-1.2} \frac{\text { curies }}{\text { megawatt-sec }},
\end{aligned}
$$

where $0.5 \frac{\text { mev }}{\text { disintegration }}$ and $3.7 \times 10^{10} \frac{\text { disintegrations } / \mathrm{sec}}{\text { curie }}$ are assumed.

If it requires time $t_{0}$ for the cloud to reach $x_{o}$, the dose rate at $x_{0}$ at time $t>t_{0}$ is given by

$$
D_{r}(t)=D_{r}\left(t_{0}\right)\left(\frac{t}{t_{0}}\right)^{-1.2}
$$

where $D_{r}\left(t_{0}\right)$ is the dose rate at $X_{0}$ immediately after fall-out. $D\left(t, X_{0}\right)$, the accumulated dose at $x_{0}$ over some time interval, $t_{0}<t<t_{1}$, is given by

$$
D\left(t_{1}, x_{0}\right)=5 D_{r}\left(t_{0}\right) t_{0}\left[1-\left(\frac{t_{0}}{t_{1}}\right)^{0.2}\right] \text {. }
$$

Way, K., and Wigner, E. P, Phys. Rev., 70, 115 (1946).

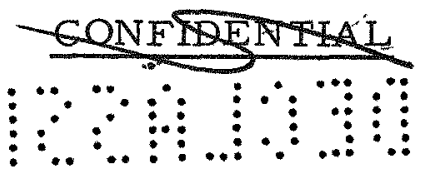




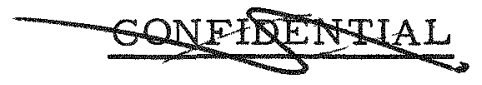

71

The value of the cloud radius, $\sigma$, at various distances downwind is obtained from the nomographs constructed by J. Z. Holland.

The results, giving the doses for various distances, stability parameters, and wind velocities, are shown in Figure 16.

\section{Inhalation Dose From Radioactive Cloud}

An observer receiving an internal dose from inhalation of a radioactive cloud from an explosion would be in danger of having the thyroid gland, bones, and lungs affected by the more hazardous fission products I131, $\mathrm{Sr}^{89}, \mathrm{Sr}^{90}+\mathrm{Y}^{90}, \mathrm{Ba}^{140}+\mathrm{La}^{140}, \mathrm{Ce}^{144}+\mathrm{Pr}^{144}$, and $\mathrm{Y}^{91}$. The shortlived fission products will also damage the lungs.

Experimental work* has shown that the lungs retain about 50 per cent of the total small particles in the inhaled air. This 50 per cent factor will be assumed to apply to all fission products inhaled. The total activity resulting from the retention of radioactive isotopes in the lungs must be fur ther reduced by an "effective" retention factor, $f_{o}$, which varies with the isotope and corresponding organ which is affected. The activity retained in an organ may be obtained from the equation

$$
\frac{\text { A(millicuries })}{\text { megawatt }-\mathrm{sec}}=(0.50)\left(16.8 \times 10^{-3}\right) \mathrm{f}_{\mathrm{O}} \frac{\mathrm{J}}{\mathrm{v}} \frac{\mathrm{Q}}{\mathrm{v}^{2 / 3}},
$$

where

$$
\begin{aligned}
\mathrm{J}= & \text { inhalation rate, } 17 \text { liters per min } \\
\mathrm{v}= & \text { cloud velocity, } \mathrm{m} \text { per sec } \\
\mathrm{Q}= & \text { total curies of given isotope in the cloud at time of } \\
& \text { inhalation per megawatt-sec } \\
\mathrm{V}= & (\sqrt{\pi} \sigma)^{3}, \mathrm{~m}^{3} \\
\sigma= & \text { radius of cloud at time of inhalation, } \mathrm{m} \\
\mathbf{f}_{\mathrm{O}}= & \text { effective retention factor. }
\end{aligned}
$$

by

The integrated lung dosage for the short-lived fission products is given

$$
\mathrm{D}=\frac{88.6}{\mathrm{v} \sigma^{2}}\left(\frac{\mathrm{v}}{\mathrm{x}}\right)^{0.2} \frac{\mathrm{r}}{\text { megawatt-sec }}
$$
"Landahl, H. D. . and Tra cewell, T. N. " On the Retention of Air Borne Particles in the Human Lang, 1 ",
TID 365. 
where it is assumed that each disintegration in the lung leads to the absorption of $0.5 \mathrm{mev}$ of energy in the lung tissue.

$$
\begin{aligned}
Q & =f e^{-\lambda\left(\frac{X}{v}\right)} \lambda \frac{3 \times 10^{16}}{3.7 \times 10^{10}} \frac{\text { curies }}{\text { megawatt-sec }} \\
& =8.11 \times 10^{5} \mathrm{f} \mathrm{e}^{-\lambda\left(\frac{X}{v}\right)} \frac{\text { curies }}{\text { megawatt-sec }} .
\end{aligned}
$$

Table 4 gives the important data for the hazardous isotopes of interest. The cloud radius at the time of inhalation was obtained from the nomographs constructed by J.Z. Holland.

The short-lived fission products were assumed to decay according to the Way-Wigner formula. The amount of activity from this source is given by Equation (D-6), where

$$
Q=2.16 \times 10^{6}\left(\frac{\mathrm{v}}{\mathrm{X}}\right)^{1.2} \frac{\text { curies }}{\text { megawatt }-\mathrm{sec}}
$$

\section{Energy Releases}

\section{Instantaneous Reactivity Additions}

The analysis presented here is an attempt to estimate the fission energy release after an instantaneous addition of reactivity. It is postulated that the reactivity is decreased only by core expansion caused by internal pressure buildup due to vaporization of fuel. The vaporization of fuel is assumed to begin after sufficient energy has been supplied to heat all of the fuel to the boiling temperature. If the core contains $10 \mathrm{~kg}$ of fuel, the energy required to reach the boiling temperature is 6.76 megawatt-sec. An additional 16.5 megawatt-sec would vaporize the fuel. The model chosen is a spherical reactor with reflector. follows:

The equations which were used to define the physical model are as

$$
\begin{aligned}
& \Delta R(t)=\frac{2 \lambda}{\rho R} \int_{0}^{t} \int_{0}^{t^{\prime}} p_{0}\left(t^{\prime \prime}\right) d t^{\prime \prime} d t^{\prime}, \\
& \frac{d P(t)}{d t}=\frac{\Delta k_{p}(t)}{l} P(t)
\end{aligned}
$$




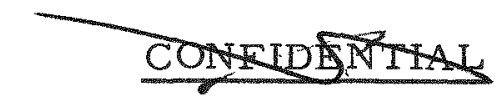

73

$$
\begin{gathered}
\Delta k_{p}(t)=\Delta k_{0}-\alpha_{1} \Delta R(t), \\
\frac{d N(t)}{d t}=\left[\frac{N_{0}-N(t)}{N_{0}}\right] \frac{P(t)}{\Delta H_{v}}, \\
p_{0}(t)=[p *(t)-p *(0)] \alpha_{2}, \\
p *(t)=\frac{\bar{R} N(t) T(t)}{V(t)}, \\
\frac{d T(t)}{d t}=\frac{P(t)}{C_{v} N_{0}}-\frac{\bar{R} C_{V}(t)}{C_{V}}\left[\frac{1}{V(t)} \frac{d V(t)}{d t}-\frac{1}{N(t)} \frac{d N(t)}{d t}\right] . \\
\frac{d V(t)}{d t}=4 \pi R^{2} \frac{d \Delta R(t)}{d t},
\end{gathered}
$$

where

$$
\begin{aligned}
t= & \text { time after vaporization begins, sec } \\
\Delta R(t)= & \text { radial distance core-reflector interface changes as } \\
& \text { a function of time, cm } \\
R= & \text { initial effective radius of core-reflector interface, } \\
& 36.8 \mathrm{~cm} \\
\mathrm{p}_{\mathrm{o}}(t)= & \text { pressure above atmospheric pressure at center of } \\
& \text { core at time } t \text { atm } \\
\rho= & \text { mean density of core } \\
\mathbf{P}(t)= & \text { reactor power at time } t, \text { megawatts } \\
\Delta \mathrm{k}_{\mathrm{p}}(t)= & \text { prompt excess multiplication at time } t=\mathrm{k}_{\mathrm{eff}}(1-\beta)-1 \\
\mathrm{k}_{\mathrm{eff}}= & \text { effective multiplication factor } \\
l= & \text { mean neutron generation time, sec } \\
\Delta \mathrm{k}_{\mathrm{O}}= & \text { initial value for } \Delta \mathrm{k}_{\mathrm{p}}(\mathrm{t}) \\
\alpha_{1}= & \text { core expansion reactivity coefficient, cm-1 }
\end{aligned}
$$




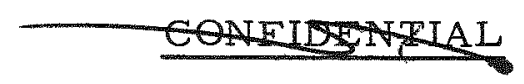

74

$$
\begin{aligned}
& N(t)=\text { number of } g-\text { moles of uranium-235 in gas phase at time } t \\
& \mathbf{N}_{\mathrm{O}}=\text { number of } \mathrm{g} \text {-moles of uranium-235 in core } \\
& \Delta \mathrm{H}_{\mathrm{v}}=\text { heat of vaporization, megawatt-sec per } \mathrm{g} \text {-mole } \\
& p *(t)=\text { average gas pressure in core at time } t \text {, atm } \\
& T(t)=\text { temperature of gas phase at time } t, K \\
& V(t)=\text { volume of gas phase at time } t \text {, liters } \\
& \overline{\mathbf{R}}=\text { gas constant, } \frac{\text { liter }-\mathrm{atm}}{\mathrm{g}-\mathrm{mole} / \mathrm{K}} \\
& \mathrm{C}_{\mathrm{V}}=\text { heat capacity of gas phase at constant volume, } \\
& \frac{\text { liter-atm }}{\mathrm{g}-\mathrm{mole} / \mathrm{K}} \text { or } \frac{\text { megawatt-sec }}{\mathrm{g}-\mathrm{mole} / \mathrm{K}} \text {. }
\end{aligned}
$$

Equation (D-9) is an approximate solution of the equation of motion for mass particles in the core. This equation is obtained in a manner similar to that employed by Mills*, except the pressure variation in time is not assumed to be known. The parameter $\lambda$, following Mills, is taken to be $1 / 3$.

Equation (D-10) relates the rate of power rise with the multiplication and power at time t. It is approximate in that delayed neutrons are neglected, but since prompt critical conditions are of interest this is not serious. The mean generation time, $l$, was calculated to be approximately $3.6 \times 10^{-5} \mathrm{sec}$.

Equation (D-11) relates the core expansion to the reactivity. The coefficient $\alpha_{1}$ was calculated to be 0.0224 .

Equation (D-12) relates the rate of vaporization of fuel to the power level and the number of moles already vaporized. The values of $N_{0}$ and $\Delta \mathrm{H}_{\mathrm{V}}$ are 42.5 moles and 0.389 megawatt-sec per mole, respectively. It is assumed that only fissions which occur in the solid phase are effective in vaporizing fuel. The fissions occurring in the dense gas phase are assumed to increase the internal energy of the gas.

Equation (D-13) relates the pressure at the core center to the average pressure in the gas core. The constant $\alpha_{2}$ was calculated to be 1.25 .

Equation (D-14) is the perfect gas law and Equation $(D-15)$ is an energy balance for the gas phase. Equation (D-16) is an approximate equation relating the rate of gas-volume change to the core expansion.

Mills, M. M., "On the Hazards Due to Nuclear Reactors", Reactor Science and Technology, p 55.

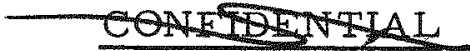




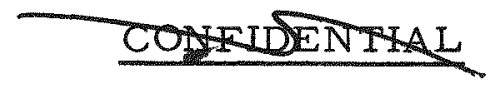

75 and 76

Equations (D-9) and (D-16) were solved by means of an electronic operational analog. The initial conditions were chosen so that for a given value of $\Delta \mathrm{k}_{\mathrm{O}}$, the power level was such that 6.76 megawatt-sec had already been supplied, i.e.,

$$
P(0)=6.76 \text { megawatt-sec }\left(\frac{\Delta \mathrm{k}_{0}}{l}\right) .
$$

The transient was terminated when $k_{p}(t)=0$ and the fission energy of the transient was obtained. The results of several determinations of the energy release for different values of $\Delta \mathrm{k}_{\mathrm{o}}$ are noted in Figure 18.

\section{Gradual Reactivity Addition}

The energy release for the case of maximum rate of reactivity addition upon closure ( $\$ 3.20 / \mathrm{sec}$ ) was calculated as follows: An approximation for the inverse period, $p$, when an energy $E$ has been generated is

$$
\mathrm{p}^{2}=\frac{2}{l} \frac{\mathrm{dk}}{\mathrm{dt}} \ln \frac{\mathrm{Ep}}{\mathrm{P}_{\mathrm{o}} 10^{2}}
$$

where

$$
\begin{aligned}
\frac{d k}{d t} & =\text { rate of reactivity addition, } \sec ^{-1} \\
E & =6.76 \text { megawatt }-\mathrm{sec} \\
P_{O} & =\text { startup power, megawatts. }
\end{aligned}
$$

Taking $\frac{\mathrm{dk}}{\mathrm{dt}}$ equal to $0.021 \Delta \mathrm{k} / \mathrm{k}$ per $\mathrm{sec}$ and $P_{\mathrm{o}}=5 \times 10^{-10}$ megawatt, it is found that $\mathrm{p}=169 \mathrm{sec}^{-1}$ and this corresponds to an instantaneous addition of $\Delta \mathrm{k}_{\mathrm{p}}=0.00610$. Approximately 1 millisecond is required to disassemble the core after $E=6.76$ megawatt-sec for this case and hence the reactivity added during this time is negligible. Consequently, Equation $(D-17)$ may be used in conjunction with Figure 18 in order to estimate the fission-energy release for the addition of reactivity upon closure.

\section{CGAISTLL}




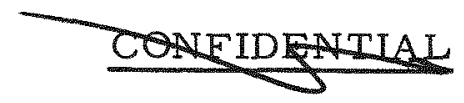

77

APPENDIX E

\section{MISCELLANEOUS CALCULATIONAL METHODS}

\section{Effect of Safety and/or Control Plates}

The effect of the control plates was estimated by the usual two-group method based on an equivalent bare reactor. The model used assumed a poison sheet, black to thermal neutrons, separating the core into two equal halves. The problem solved may be stated in the following manner:

$$
\begin{aligned}
& D_{1} \nabla^{2} \phi_{1}-\Sigma_{1} \phi_{1}+k_{a 2} \phi_{2}=0, \\
& D_{2} \nabla^{2} \phi_{2}-\Sigma_{a 2} \phi_{2}+\Sigma_{1} \phi_{1}=0 . \\
& \phi_{1 x}^{1}(x=0)=0, \\
& \phi_{2_{x}}(x=0)=0, \\
& \phi_{1_{x}}(a+\delta)=\phi_{2 x}(a+\delta)=0,
\end{aligned}
$$

where $\phi_{1}$ and $\phi_{2}$ are the $x$ components of the fast and slow fluxes respectively, $a$ is the half dimension of the core in the $x$ direction, and $\delta$ is half the reflector savings.

The effect of individual plates $4-1 / 2$ in. wide was estimated using a flux-squared weighting function.

II. Moderator Temperature Coefficient

The moderator temperature coefficient was estimated assuming that the plastic can expand in the vertical direction only. The two-group bare reactor criticality equation is:

$$
\begin{gathered}
k_{\text {eff }}=\frac{\eta f}{1+M^{2} B^{2}} \\
\frac{d k_{e f f}}{d T}=\frac{\partial k}{\partial(\eta f)} \frac{\partial(\eta f)}{\partial T}+\frac{\partial k}{\partial M^{2}} \frac{\partial M^{2}}{\partial T}+\frac{\partial k}{\partial B^{2}} \frac{\partial B^{2}}{\partial T} .
\end{gathered}
$$




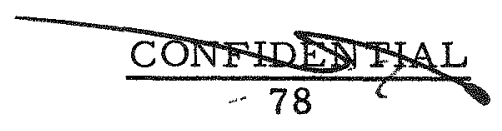

It will be assumed that $\eta$ and $B^{2}$ do not change with temperature enough to affect the results significantly.

$$
\begin{aligned}
& \frac{\partial k}{\partial(\eta f)}=\frac{1}{1+M^{2} B^{2}} \\
& \frac{\partial \mathrm{k}}{\partial \mathrm{M}^{2}}=-\frac{k_{\mathrm{eff}} \mathrm{B}^{2}}{1+\mathrm{M}^{2} \mathrm{~B}^{2}} \\
& \frac{\partial(\eta f)}{\partial T}=\frac{\partial(\eta f)}{\partial \rho} \quad \frac{\partial \rho}{\partial T} \quad \text { and } \quad \frac{\partial M^{2}}{\partial T}=\frac{\partial M^{2}}{\partial \rho} \quad \frac{\partial \rho}{\partial T} \\
& \rho=\frac{\rho_{\circ \alpha}}{1+\alpha \Delta \mathrm{T}} \\
& \frac{\partial \rho}{\partial T}=-\frac{\rho_{0} \alpha}{1+\alpha \Delta T} \\
& M^{2}=M_{0}^{2}\left(\frac{\rho_{0}}{\rho}\right)^{2} \\
& \eta f=\eta \frac{\Sigma_{a_{\text {fuel }}}}{\Sigma_{a_{\text {fuel }}+\Sigma_{a_{A l}}+\Sigma_{a_{\text {mod. }}}}} \text {, } \\
& \Sigma_{a_{\bmod }}=\Sigma_{a 0_{\bmod }} \frac{\rho}{\rho_{0}}, \\
& \frac{\partial M^{2}}{\partial \rho}=-\frac{2 M_{0}^{2} \rho_{0}^{2}}{\rho^{3}} \\
& \frac{\partial(\eta f)}{\partial \rho}=-\frac{\eta f \frac{\partial \Sigma_{a_{\text {mod. }}}}{\partial \rho}}{\Sigma_{a_{\text {fuel }}+\Sigma_{a_{A l}}+\Sigma_{a_{\text {mod. }}}}},
\end{aligned}
$$

where

$\alpha=$ linear coefficient of expansion of polyethylene

$\rho_{0}=$ density of polyethylene at room temperature

$\Delta T=$ temperature $r$ ise in polyethylene.

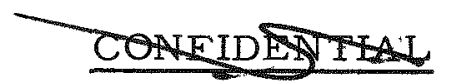




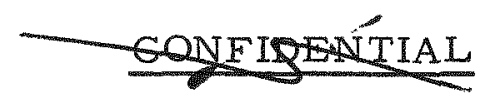

79

Substituting these qualities into Equation $(E-1)$ :

$$
\frac{1}{k_{\text {eff }}} \frac{\mathrm{dk}_{\mathrm{eff}}}{\mathrm{dT}}=\frac{\alpha}{(1+\alpha \Delta \mathrm{T})^{2}}\left[f \frac{\Sigma_{\mathrm{a}_{\text {mod. }}}}{\Sigma_{\mathrm{a}_{\text {fuel }}}}-\frac{2 \mathrm{M}_{\mathrm{o}}{ }^{2} \mathrm{~B}^{2}(1+\alpha \Delta \mathrm{T})^{3}}{1+\mathrm{M}_{\mathrm{o}}{ }^{2} \mathrm{~B}^{2}}\right] \text {. }
$$

III. Reactivity as a Function of Gap Separation

The method used in this problem is identical to that used in the controlplate problem except the boundary conditions at the center were changed to:

$$
\begin{aligned}
& \phi_{1}^{\prime}(x=0)=f_{1}(h) \phi_{1_{x}}(x=0), \\
& \phi_{2_{x}^{\prime}}^{\prime}(x=0)=f_{2}(h) \phi_{2_{x}}(x=0),
\end{aligned}
$$

where

$$
f_{i}(h)=\frac{3}{2 \lambda_{i}}\left[\frac{1-\gamma h k_{1}(\gamma h)+2 / 3\left(\gamma \lambda_{i}\right)(\gamma h) e^{-\gamma h}}{1+(1+\gamma h) e^{-\gamma h}}\right],
$$

and

$$
\begin{aligned}
\lambda_{i} & =\text { mean free path } \\
\gamma^{2} & =\text { buckling }-\left[\frac{\pi}{2(a+\delta)}\right]^{2} \\
h & =\text { separation distance between halves } \\
a & =1 / 2 \text { core width. }
\end{aligned}
$$

The boundary conditions at the center were taken from Tamor*.

Tamor, $S_{*}$ "Effect of Gap on Plle Reactivity" ORNL-1320.

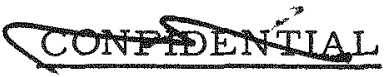




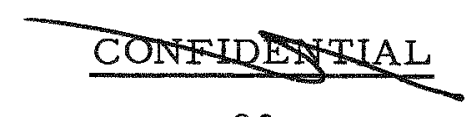

80

Constants Used in the Calculations

\begin{tabular}{|c|c|c|}
\hline Symbol & Definition & Values \\
\hline$\tau$ & 1/6 mean square slowing down length & 58 and $90 \mathrm{~cm}^{2}$ \\
\hline$L^{2}$ & 1/6 mean square diffusion length & 2 and $4 \mathrm{~cm}^{2}$ \\
\hline$B^{2}$ & Buckling & $4.62 \times 10^{-5}$ per $\mathrm{cm}^{2}$ \\
\hline$\delta$ & Reflector savings & $10 \mathrm{~cm}$ \\
\hline \multicolumn{2}{|c|}{ Reactor dimensions } & $60-\mathrm{cm}$ cube \\
\hline$\eta\left(\mathrm{U}^{235}\right)$ & & $\begin{array}{l}\text { 2. } 078 \text { neutrons per } \\
\text { absorption }\end{array}$ \\
\hline$\alpha$ & $\begin{array}{l}\text { Linear coefficient of thermal expan- } \\
\text { sion for polyethylene }\end{array}$ & $8 \times 10^{-5}$ per $C$ \\
\hline$\rho_{\circ}$ & Density of polyethylene & $0.92 \mathrm{~g} \mathrm{per} \mathrm{cm}^{3}$ \\
\hline$\Delta \mathrm{T}$ & Temperature increase of polyethylene & $0 \mathrm{C}$ and $100 \mathrm{C}$ \\
\hline$f \frac{\Sigma_{a_{\text {mod. }}}}{\Sigma_{a_{\text {fue }}}}$ & Moderator thermal utilization & 0.393 and 0.205 \\
\hline$\lambda_{1}$ & "Fast" mean free path & $4.470 \mathrm{~cm}$ \\
\hline$\lambda_{2}$ & Thermal mean free path & $1.081 \mathrm{~cm}$ \\
\hline$\gamma$ & {$\left[\mathrm{B}^{2}-\left(\frac{\pi}{2(\mathrm{a}+\delta)}\right)^{2}\right]^{1 / 2}$} & $0.0555 \mathrm{~cm}^{-1}$ \\
\hline
\end{tabular}

